Check for updates

Cite this: RSC Adv., 2017, 7, 28186

Received 18th April 2017

Accepted 22nd May 2017

DOI: $10.1039 / \mathrm{c} 7 \mathrm{ra04368f}$

rsc.li/rsc-advances

\section{Electrochemical migration of Sn and Sn solder alloys: a review}

\author{
Xiankang Zhong, (D)*ab Longjun Chen, ${ }^{a}$ Bálint Medgyes, ${ }^{c}$ Zhi Zhang, ${ }^{a}$ Shujun Gao ${ }^{d}$ \\ and László Jakabc
}

Sn and Sn solder alloys in microelectronics are the most susceptible to suffer from electrochemical migration (ECM) which significantly compromises the reliability of electronics. This topic has attracted more and more attention from researchers since the miniaturization of electronics and the explosive increase in their usage have largely increased the risk of ECM. This article first presents an introductory overview of the ECM basic processes including electrolyte layer formation, dissolution of metal, ion transport and deposition of metal ions. Then, the article provides the major development in the field of ECM of Sn and Sn solder alloys in recent decades, including the recent advances and discoveries, current debates and significant gaps. The reactions at the anode and cathode, the mechanisms of precipitates formation and dendrites growth are summarized. The influencing factors including alloy elements $(\mathrm{Pb}$, $\mathrm{Ag}, \mathrm{Cu}, \mathrm{Zn}$, etc.), contaminants (chlorides, sulfates, flux residues, etc.) and electric field (bias voltage and spacing) on the ECM of Sn and Sn alloys are highlighted. In addition, the possible strategies such as alloy elements, inhibitor and pulsed or AC voltage for the inhibition of the ECM of Sn and Sn solder alloys have also been reviewed.

\section{Introduction}

The growing miniaturization of electronic systems and the explosive increase in their usage have increased the failure risk in electronics. The higher density packaging has resulted in smaller components, closer spacing, thinner metallic parts, and higher gradient of electric fields. Moreover, the electronics sometimes have to operate in humid and even polluted environment. Consequently, the electronics materials are more susceptible to failure. It is reported that even small amounts of weight loss, of the order of nanograms or less, can cause problems and ultimately lead to device failure. ${ }^{1}$

Electrochemical migration (ECM) is a common reliability problem which is related to failure encountered in the electronics industry. It is defined as a process by which a metal, in contact with insulating materials and under an electrical potential, is removed ionically from its initial location and is redeposited at other location. This migration often results in lowered resistance and dielectric failure. ${ }^{2}$ ECM is

${ }^{a}$ State Key Laboratory of Oil and Gas Reservoir Geology and Exploitation, School of Oil and Natural Gas Engineering, Southwest Petroleum University, Chengdu 610500, P. R. China. E-mail: zhongxk@yeah.net; Tel: +86-028-83032210

${ }^{b}$ Max-Planck Institut für Eisenforschung, Max-Planck Str. 1, D-40237 Düsseldorf, Germany

'Department of Electronics Technology, Budapest University of Technology and Economics, Budapest H-1111, Hungary

${ }^{d}$ Department of Chemical \& Biomolecular Engineering, Ohio University, OH 45701, USA fundamentally an ionic process and requires electrolyte, bias voltage and time. Therefore, ECM is totally different from solidstate electro-migration which is the mass transport of metal under dry conditions due to the momentum transfer between conducting electrons and diffusing metal atoms. ${ }^{3}$ This process is also different from the whisker growth which is induced by compressive mechanical stress in electronics. ${ }^{4,5}$

The phenomenon of ECM was first observed in the late 1940s and early 1950s. Silver migration first caused large scale problems in Post Office equipment where contact springs were silver-plated in an attempt to reduce contact resistance. ${ }^{2}$ With the growing miniaturization of electronics and the explosive increase in their usage, ECM has attracted much attention because more and more reliability problems related to ECM encountered in electronics. Extensive work has been conducted on the ECM of various electronic materials such as $\mathrm{Cu},{ }^{6-23}$ $\mathrm{Ag},{ }^{24-41} \mathrm{Sn}$ and Sn solder alloys, ${ }^{42-76}$ as well as other metals. ${ }^{41,77-80}$

Steppan et al. ${ }^{2}$ contributed a critical review of corrosion failure mechanisms of electronic materials. The ECM of Ag, $\mathrm{Cu}$ and Au was reviewed in detail. However, the ECM of Sn and Sn solder alloys was not covered in their review paper. In electronics, the metallic surfaces that are directly exposed to the environment are mainly the component electrodes, solder joints, and contact/connector areas. Nowadays, hot air solder leveling (HASL) surface finishes are widely employed with Sn based solder in industrial applications. ${ }^{42,81}$ Therefore, it can be considered that large part of the exposed areas is made of Sn or Sn solder alloys. ${ }^{42}$ In this case, the ECM of Sn and Sn solder 
alloys is extremely important in connection with reliability of electronic devices. As mentioned above, the behaviors and mechanisms of Sn and Sn solder alloys have been extensively investigated in the recent decades. ${ }^{42-76}$ For more in depth knowledge in the future work, a critical review of the ECM of Sn and Sn solder alloys is therefore needed.

This work mainly focuses on the fundamentals of ECM, and the state-of-the-art in ECM studies of Sn and Sn solder alloys. Namely, the first objective of this paper is to introduce the fundamentals of ECM including the basic processes, characteristics and significance. The second objective is to review the recent advances and discoveries, current debates and significant gaps in the field of ECM of Sn and Sn solder alloys.

\section{The fundamentals of electrochemical migration}

ECM occurs when two oppositely biased and closely spaced electrodes (circuits, joints or legs of components) are connected by a continuous electrolyte layer which may be a visible electrolyte layer or an invisible adsorbed layer. Some parts of metal become ionized and begin to migrate under the applied electric field. Then, a conducting filament forms between the anode and cathode, which can lead to short circuit failure of the electronics. There are two mechanisms mainly responsible for the ECM phenomena: the formation of conducting anodic filaments and dendrite growth. ${ }^{\mathbf{2 2}}$

The conducting anodic filaments which usually consist of metal salts emanate from the anode to the cathode. ${ }^{83}$ Lee et al. ${ }^{82}$ used a four-layered printed circuit board with an electroplated through-a-hole to determine the ECM characteristics of eutectic $\mathrm{Sn}-\mathrm{Pb}$ solder at the $85{ }^{\circ} \mathrm{C} / 85 \% \mathrm{RH}$ condition. As is shown in Fig. 1, it is seen that conducting anodic filaments are formed near the anode.

For Sn and Sn solder alloys, most studies focus on the second ECM phenomenon: dendrite growth. Metal ions are produced at the anode and then migrate towards the cathode, where they can be reduced to metallic dendrite which then grows towards the anode. For example, the scanning electron microscopy images of Sn dendrites are shown in Fig. 2. As soon as the

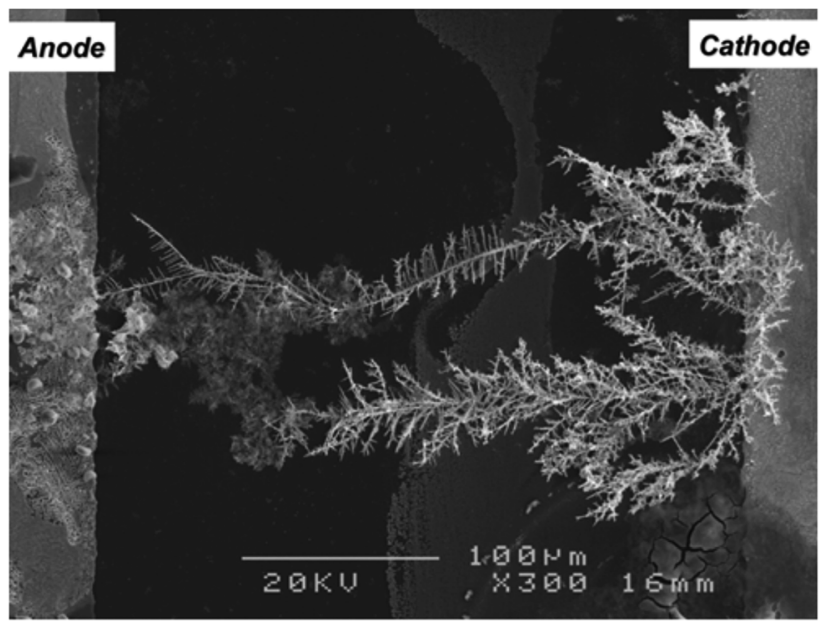

Fig. 2 Morphology of the dendrites formed by water drop test for Sn$58 \mathrm{Bi}$ solder alloy in $0.001 \mathrm{wt} \% \mathrm{Na}_{2} \mathrm{SO}_{4}$ at a bias voltage of $2 \mathrm{~V}$. Reproduced with permission from ref. 61. Copyright 2010, Springer.

dendrite reaches the anode, the short circuit occurs and causes the failure of electronics.

Since the number of studies on dendrite growth phenomenon of Sn and Sn solder alloys are far more than conductive anodic filaments, the following introduction of the fundamentals is based the ECM phenomenon of dendrite growth. The ECM can be considered as a consecutive four-step process: (i) electrolyte layer formation, (ii) dissolution of metal, (iii) ion transport and (iv) deposition of metal ions. This four-step process is schematically shown in Fig. 3 where Fig. 3a-e indicate the sample without an electrolyte layer, the sample with an electrolyte layer, dissolution of metal, ion transport and deposition of metal ions (dendrites growth), respectively. Once the dendrite bridges the two solder joints, the shirt circuit will occur and subsequently lead to device failure.

\subsection{Electrolyte layer formation}

The electrolyte layer formation which is also called as path formation $^{\mathbf{1 1 , 8 4}}$ refers to the formation of a continuous moisture film or a condensed water layer/drop which can bridge the gaps
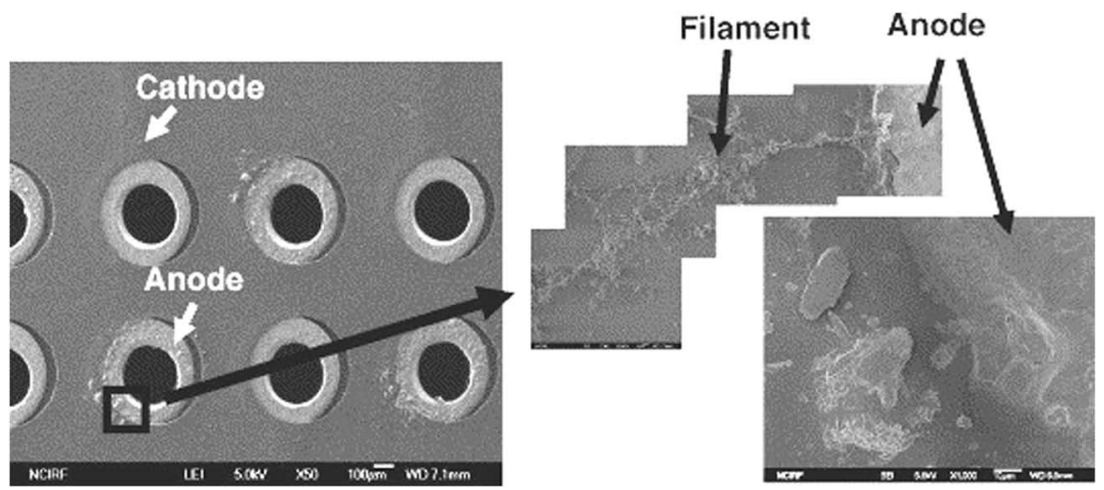

Fig. 1 Morphology of conductive anodic filaments around the anode at through-hole-via in the PCB after $140 \mathrm{~h}$ at $85^{\circ} \mathrm{C}, 85 \% \mathrm{RH}$. Reproduced with permission from ref. 82. Copyright 2006, Elsevier 


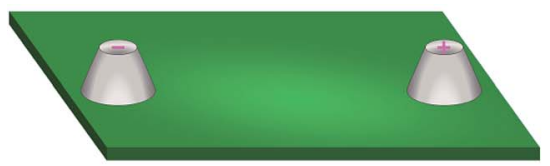

(a)

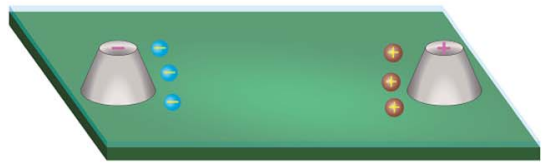

(c)

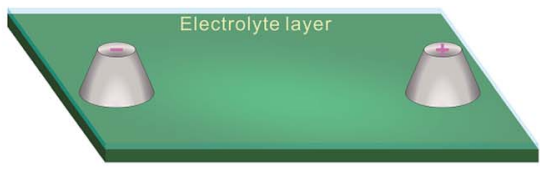

(b)

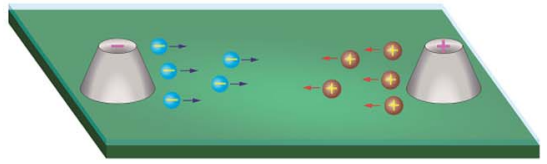

(d)

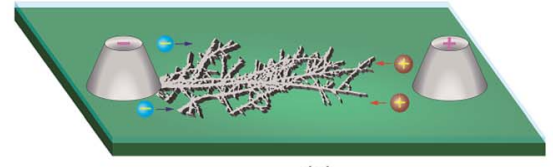

(e)

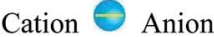

Fig. 3 The schematic diagrams of Sn solder alloys joints (a) ECM sample, and ECM process: (b) electrolyte layer formation, (c) dissolution of metal, (d) ion transport and (e) deposition of metal ions (dendrites growth).

of oppositely biased electrodes. The presence of this electrolyte layer is the precondition for the ECM to occur. Electrolyte layer formation depends upon the relative humidity, contaminant, temperature, and surface conditions of materials in electronics.

To cause ECM, humidity is necessary, where a moisture layer of a few monolayers is fully sufficient. Lee $e t a l .{ }^{85}$ reported that a certain number of layers sufficient to start corrosion processes will be formed on metal surface at a critical humidity of about $60 \%$ to $70 \%$ at room temperature, depending on the substrate polarity and its surface energy. Moreover, hygroscopic contaminants such as chlorides apparently lower the critical humidity of adsorption. E.g., the materials which are exposed to contaminated atmospheres of relative humidity as low as $40 \%$ are still covered by electrolyte layers of a thickness of several monolayers. ${ }^{86,87}$ As the temperature changes, the relative humidity of the air also changes. If the temperature drops to below the dew point compared to the surrounding air, the relative humidity will at some point exceed $100 \%$ and a layer of water can be formed on the surface. ${ }^{88}$ When the temperature rises again, the water evaporates and the water layer becomes thinner and thinner or even totally disappears. In addition, some factors related to surface conditions including chemical constituents of fluxes applied for soldering, the composition of the board materials such as laminate and board finish, and surface roughness will also affect the formation of electrolyte layer. ${ }^{7}$ Therefore, as the precondition for the ECM to occur, the electrolyte layer formation is affected by multiple factors, making it relatively complicated.

From the corrosion electrochemistry point of view, a change in the thickness of the electrolyte layer affects a number of processes, e.g., the mass transport of dissolved oxygen, the accumulation of products, and the hydration of dissolved metal ions. ${ }^{89-93}$ Likewise, a change in thickness of the electrolyte layer will also apparently affect the ECM process. Warren et al. ${ }^{94}$ compared the ECM behaviors of $\mathrm{Cr}-\mathrm{Cu}-\mathrm{Cr}$ metallization under three types of experimental conditions including bulk solution, thin electrolyte layer and adsorbed moisture layer. It was found that dendrite morphology and dendrite growth rates were nearly identical for immersion tests in both bulk solution and thin electrolyte layer, but were quite different in adsorbed moisture layer. Zhong et al. ${ }^{50}$ investigated the ECM behavior of Sn under the electrolyte layer with different thicknesses from 30 $\mu \mathrm{m}$ to $1000 \mu \mathrm{m}$ and found that dendrite growth rate first decreased and then increased with decreasing thickness of electrolyte layer. Apparently, the thickness of electrolyte layer is of significance in understanding the ECM mechanism.

However, until now there are two main limitations in quantitative analysis the effect of electrolyte layer thickness on ECM. On the one hand, most of the studies on ECM mechanisms were performed using water drop test or thin electrolyte layer test where the exact thickness of electrolyte layer could be known, ${ }^{95}$ however, such tests could not adequately represent failure processes which actually occur in ultra-thin layers of moisture collected from ambient air. On the other hand, the exact thickness of the moisture layer has never been unknown if the ECM test is performed using simulated environment tests such as the thermal humidity bias test where just the relative humidity and temperature are controlled. ${ }^{28}$ Actually, there are several techniques such as ellipsometry, ${ }^{96}$ sum-frequencygeneration vibrational spectroscopy and scanning polarization force microscopy, ${ }^{97}$ attenuated total reflection infrared spectroscopy $^{98}$ and ambient-pressure X-ray photoelectron spectroscopy $^{99,100}$ that can be used to in situ measure the thickness of ultra-thin electrolyte layer, even a few monolayers of water. Therefore, it can be expected that the exact thickness of electrolyte layer in the simulated environment tests of ECM can be known in the future.

\subsection{Dissolution of metal}

The bias voltage applied across the closely spaced electrodes is usually in the voltage-range from a few volts up to several hundred volts in operating conditions of electronics. ${ }^{18,19}$ Therefore, the dissolution of metal will occur in the presence of 
a continuous electrolyte layer which bridges the anode and cathode, as described by reaction (1):

$$
\mathrm{M} \rightarrow \mathrm{M}^{n+}+n \mathrm{e}^{-}
$$

where $\mathrm{M}$ represents the metal and $n$ is the number of electrons involved in this reaction. As the dissolution of metal occurs, the other half reactions on cathode are also proceeding simultaneously. E.g., the reduction of oxygen, as described in reaction (2):

$$
\mathrm{O}_{2}+2 \mathrm{H}_{2} \mathrm{O}+4 \mathrm{e}^{-} \rightarrow 4 \mathrm{OH}^{-}
$$

Accordingly, other ions such as $\mathrm{OH}^{-}$are also formed in electrolyte layer during the dissolution of metal.

The dissolution of metal is of utmost significance for ECM because it supplies the metal ions and other ions for the subsequent steps. To some extent, the dissolution rate can determine the whole ECM process. Takemoto et al. ${ }^{76}$ investigated ECM of Sn and Sn solder alloys in distilled water and found that large anodic dissolution rate seemed to be responsible for high ECM susceptibility. Minzari et al. ${ }^{42}$ studied the ECM of Sn under water drop with different $\mathrm{Cl}^{-}$and $\mathrm{Br}^{-}$ concentrations. It was found that the ECM probability first increased and then decreased with increasing anodic dissolution rate of Sn if all parameters were held constant except $\mathrm{Cl}^{-}$ and $\mathrm{Br}^{-}$concentrations in water drop. Jung et al. ${ }^{65}$ reported the dissolution of $\mathrm{Sn}$ at the anode was probably the ratedetermining step of ECM of $\mathrm{Sn}-3.0 \mathrm{Ag}-0.5 \mathrm{Cu}$ solder in $\mathrm{NaCl}$ solution and $\mathrm{Na}_{2} \mathrm{SO}_{4}$ solution. Barton and Bockris ${ }^{101}$ used silver wire as an anode to investigate the dendrites growth of silver in liquid sodium nitrate and potassium nitrate. They found that for a given electrode and concentration, a critical current density existed below which no dendrites formed. This critical current density was proportional to the concentration of $\mathrm{Ag}^{+}$ which was related to the anodic dissolution of Ag. All of these studies demonstrate that dissolution of metal plays a key role in ECM and this step should significantly be taken into consideration in analysis of ECM mechanism.

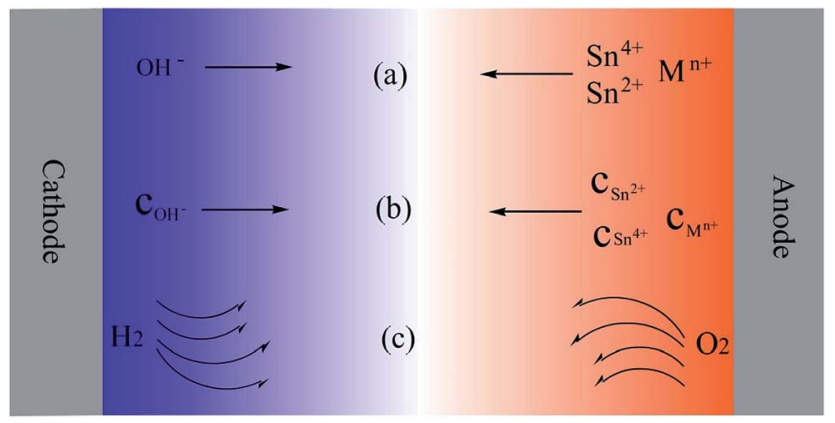

Fig. 4 Schematic diagrams of ion transport in electrochemical migration of Sn solder alloys (a) electrical migration, (b) diffusion and (c) convection. The blue color represents the concentration distribution of $\mathrm{OH}^{-}$and the orange color represents the concentration distribution of $\mathrm{Sn}^{4+}, \mathrm{Sn}^{2+}$ and $\mathrm{M}^{n+}$ (M represents alloy element in $\mathrm{Sn}$ solder alloys) in electrolyte layer.

\subsection{Ion transport}

The metal ions and other species are transported by electrical migration, diffusion and/or convection, as schematically illustrated in Fig. 4 in which the ion transport during the ECM of Sn solder alloy is taken as an example. The bias voltage applied across the two electrodes generates an electric field between cathode and anode. When an electric field is applied to ions in an electrolyte, the ions will move with the electric field. This phenomenon can be called as electrical migration. These ions migrate through the electrolyte with a characteristic velocity. The migration velocity of an ion is determined by ion mobility and the magnitude of the electric field, as is described in eqn $(3),{ }^{102}$

$$
v=\mu E
$$

where $v$ represents the velocity in $\mathrm{m} \mathrm{s}^{-1}, \mu$ is the ion mobility in $\mathrm{m}^{2} \mathrm{~V}^{-1} \mathrm{~s}^{-1}$, and $E$ is the magnitude of the applied electric field in $\mathrm{V} \mathrm{m}^{-1}$. For ECM, $E$ is a function of bias voltage applied across the electrodes and the distance between the electrodes, while, ion mobility is dependent on the characteristics of the ion itself (charge, shape and size) and the properties of the electrolyte ( $\mathrm{pH}$, temperature, viscosity, etc.). ${ }^{102}$ During the ECM, the cations such as metal ions move towards the cathode, and the $\mathrm{OH}^{-}$as well as other anions move towards the anode.

As the ECM proceeds, metal ions and other species are produced, resulting in the presence of concentration gradients over the distance between the cathode and anode, and consequently causing diffusion. For example, the concentrations of metal ions at the anode are much higher than that at the cathode, while the concentration of $\mathrm{OH}^{-}$at the cathode is much higher than that at the anode, as schematically illustrated in Fig. 4 in which the blue color represents the concentration distribution of $\mathrm{OH}^{-}$and the orange color represents the concentration distribution of metals in the electrolyte layer. The concentration gradients will drive the ions to move from a region of high concentration to a region of low concentration.

Convection is another way to transport the ions during the ECM process. For the corrosion under thin electrolyte layers, the convection is usually neglected, since the electrolyte is assumed stagnant and thin enough to neglect the effect of natural convection. ${ }^{103}$ However, the convection could apparently affect the ion transport during the ECM process in condensed conditions. E.g., a strong convection could be caused by the collapse of hydrogen bubbles derived from the $\mathrm{H}^{+}$reduction at the cathode. ${ }^{23,42,53,104}$ This influence becomes more obvious if a higher bias voltage is applied between the cathode and anode. Additionally, the electro-convection may also affect the dendrites formation (deposition of metal ions) during the ECM. Fleury et al. ${ }^{\mathbf{1 0 5}, \mathbf{1 0 6}}$ found the space charge could create an electroconvection in the vicinity of dendrites, affecting the concentration distribution of ions, and subsequently, the deposition kinetics was changed. 


\subsection{Deposition of metal ions}

Once the metal ions reach the cathode, the deposition will occur, as described in reaction (4).

$$
\mathrm{M}^{n+}+n \mathrm{e}^{-} \rightarrow \mathrm{M}
$$

The shape and morphology of the electrodeposit and surface roughness strongly depend on the path of current flow and the concentrations of species involved in the electrolytic processes. ${ }^{107,108}$ The deposition of metal ions in ECM occurs under a thin electrolyte layer or a moisture electrolyte film where an uneven current distribution on the surface of electrode usually exists under such a layer or film due to the high solution resistance and the difficulties in species transport. ${ }^{\mathbf{4 2 , 1 0 9}}$ Consequently, preferential nucleation and growth may occur at some locations of cathode, and thereby dendrites grow, as shown in Fig. 2 and 3e.

The dendrite formation consists of two consecutive stages: initiation and propagation. A critical overpotential is a necessity for the dendrite initiation. Shyu ${ }^{\mathbf{1 1 0}}$ studied the electrodeposition of copper in $\mathrm{CuSO}_{4} / \mathrm{H}_{2} \mathrm{SO}_{4}$ solution and he reported $500 \mathrm{mV}$ as the critical overpotential for copper dendrite formation. Similarly, Popov et al. ${ }^{\mathbf{1 1 1}}$ reported a critical overpotential of $550 \mathrm{mV}$ for copper dendrite formation in $\mathrm{CuSO}_{4} / \mathrm{H}_{2} \mathrm{SO}_{4}$ solution where a platinum electrode was as a cathode. For the initiation of dendrite during the ECM process in electronics, such an overpotential is usually alternatively represented by a critical bias voltage which is applied across the anode and cathode.

Meanwhile, a dendritic precursor is also needed at the beginning of the initiation stage, which will determine where the preferential nucleation to start. However, it is still not clear what a precursor is. Steppan et al. ${ }^{2}$ summarized three possibilities: a surface imperfection, a screw dislocation pyramid of the metal crystal, and a surface roughness element formed by the codeposition of foreign species. The appearance of the precursor disturbs the flow of current towards the electrode, causing the deposition rate at the peak of the precursor to be higher than that of the flat electrode surface. Consequently, a protrusion is gradually developed, where a complete characteristic of a dendrite at the end of the initiation stage can be found.

Usually, large part of the time is spent on initiation stage, rather than the propagation stage. E.g., Xia et al. ${ }^{73}$ in situ observed on the ECM of Sn-8Zn-3Bi solder joint under a water drop and found that initiation time is much longer than propagation time. Zhong et al. ${ }^{53}$ studied the ECM of Sn under 100 $\mu \mathrm{m}$-thick electrolyte layer containing $1 \mathrm{mM} \mathrm{Cl}^{-}$with a bias voltage of $3 \mathrm{~V}$. They found that the initiation stage took about 100 seconds while the total ECM time (from the beginning of ECM test to the time when a short circuit occurs) was 119 seconds. Minzari et al. ${ }^{45}$ reported a similar phenomenon during the ECM of $\mathrm{Sn}-37 \mathrm{~Pb}$ solder alloy in $10 \mathrm{ppm} \mathrm{NaCl}$ solution at a bias voltage of $3 \mathrm{~V}$.

During the propagation stage, a dendrite with a needle or tree-like shape has a faster growth rate at its tip than that of the rest of the electrode surface. Several reasons can be used together or separately to explain this special phenomenon. On the one hand, the electric field strength at the tip is greater than at the flat surface. This is because as the dendrite grows, the distance between the tip of dendrite and the anode is reduced, which will cause a stronger electric field at the dendrite tip, thereby making subsequent deposition of metal ions at the dendrite tip. ${ }^{42}$ On the other hand, the transport path of metal ions in the electrolyte to the tip is shorter than to the electrode surface, ${ }^{73}$ resulting in the preferential deposit at the tip of dendrite. Another possible reason is that the changes in diffusion mode when the whole ECM is predominated by the diffusion. As the tip of dendrites becomes sharp, spherical diffusion of metal ions begins to replace linear diffusion, making deposit of metal ions at the tip faster than that on the electrode surface. ${ }^{2}$

As soon as the dendrite reaches the anode, the short circuit occurs and causes the failure of electronics. The time from the beginning of ECM test to the time when a short circuit occurs is called time-to-failure ${ }^{61,62,65-68}$ or time-to-short, ${ }^{49-52,71-73}$ which is an extremely important parameter used to quantitatively assess the ECM susceptibility of materials. Some investigators also called the time-to-failure as the failure time. ${ }^{60}$ However, time-tofailure is used in this work.

In addition, it is necessary to mention that not only the metal ions could be deposited at the cathode, but the metal complex ions such as $\left[\mathrm{Sn}(\mathrm{OH})_{6}\right]^{2-}$ could also be reduced to metal deposit at the cathode. ${ }^{42,53,112}$

\subsection{Study methods for the electrochemical migration}

There are four study methods for the electrochemical migration, i.e., highly accelerated stress test (HAST), thermal humidity bias (THB) test, water drop (WD) test and thin electrolyte layer (TEL) test.

In HAST, high temperatures $\left(100-175{ }^{\circ} \mathrm{C}\right)$ at controlled humidity levels (50-85\% RH) and bias voltage are employed as stress factors. ${ }^{113}$ The THB test is very similar to HAST, but its employed temperature is usually lower than that in HAST. ${ }^{47,59,70,72}$ Both HAST and THB test cannot only simulate the operating conditions of electronics but can also be performed in accelerating conditions in laboratory as well as industry assessment. However, it shows a poor availability in quantitative analysis because the parameters including the locations of the electrolyte layer formation and the thickness of electrolyte layer are uncertain. The WD and TEL tests are performed respectively by placing a drop of electrolyte and a thin electrolyte layer between adjacent oppositely biased joints or circuits. ${ }^{23,42-53,60-69}$ Both WD and TEL tests cannot simulate the electrolyte layer formation process, however, both methods show better in situ inspection availability than HAST and THB test. The detailed description about the advantages and disadvantages of study methods of ECM can be found elsewhere. ${ }^{95}$

\section{Migration process of $\mathrm{Sn}$ and $\mathrm{Sn}$ solder alloys}

Sn is susceptible to ECM, ${ }^{114}$ and worse of all that, Sn and Sn solder alloys make up a large part of the metallic materials that are directly exposed on the surface of an electronic printed 
circuit board assembly. ${ }^{\mathbf{4 3 , 1 1 5}}$ Due to these reasons the ECM of Sn and Sn solder alloys is highly significant in connection with the reliability of electronics. Therefore, it has attracted researchers' more and more attention. ${ }^{42-76}$ Table 1 is a summary of ECM studies of Sn and Sn solder alloys by various investigators (note that it is impossible to list all the literature in this table.). This table enables one to compare electrode materials, the substrate materials, and the significant experimental parameters including the spacing between electrodes, applied bias voltage, and contaminants or test environments, and the test methods used in the past investigations. The migration process, the effects of alloy elements, contaminants and electric field on ECM of Sn and Sn solder alloys, as well as the inhibition of ECM of Sn and Sn solder alloys are covered in the following sections.

\subsection{Reactions at the anode}

For Sn and Sn solder alloys, the dissolution at the anode includes the dissolution of $\mathrm{Sn}$ and the dissolution of the alloy elements such as $\mathrm{Pb}, \mathrm{Ag}, \mathrm{Cu}$, etc. The reactions related to the dissolution of $\mathrm{Sn}$ are given by reactions (5) and (6). ${ }^{42,49,51,70,71}$

$$
\begin{gathered}
\mathrm{Sn} \rightarrow \mathrm{Sn}^{2+}+2 \mathrm{e}^{-} \\
\mathrm{Sn}^{2+} \rightarrow \mathrm{Sn}^{4+}+2 \mathrm{e}^{-}
\end{gathered}
$$

$\mathrm{Sn}^{2+}$ formed by reaction (5) is stable to some extent as aqueous ion in a slightly acid solution. ${ }^{112} \mathrm{Sn}^{4+}$ formed by reaction (6) co-exists with $\mathrm{Sn}^{2+}$. Additionally, the direct oxidation of $\mathrm{Sn}$ to $\mathrm{Sn}(\mathrm{OH})_{4}$ could also occur at the anode surface, which is preferred as the $\mathrm{pH}$ increases towards the neutral side, ${ }^{\mathbf{4 2}}$ as described in reaction (7).

$$
\mathrm{Sn}+4 \mathrm{H}_{2} \mathrm{O} \rightarrow \mathrm{Sn}(\mathrm{OH})_{4}+4 \mathrm{H}^{+}+4 \mathrm{e}^{-}
$$

Although some investigators proposed that $\mathrm{Sn}$ could directly reacted with $\mathrm{OH}^{-}$at the anode during the ECM to form $\mathrm{Sn}(\mathrm{OH})_{2}$ and/or $\mathrm{SnO},{ }^{66,75}$ it seems to be impossible because the solution at the anode side is acidic based on the results of in situ $\mathrm{pH}$ inspection as the ECM proceeds. ${ }^{42,43,48,49,52,53}$

The evolution of oxygen by water dissociation could occur at the anode surface as described by reaction (8) if the bias voltage is high enough. ${ }^{62,115}$

$$
2 \mathrm{H}_{2} \mathrm{O} \rightarrow 4 \mathrm{H}^{+}+\mathrm{O}_{2}+4 \mathrm{e}^{-}
$$

The oxidation of some anions such as $\mathrm{Cl}^{-}$from contaminants is also possible, especially for conditions where a high bias voltage is used, as shown in reaction (9). ${ }^{49,53,77}$

$$
2 \mathrm{Cl}^{-} \rightarrow \mathrm{Cl}_{2}+2 \mathrm{e}^{-}
$$

Besides the electrochemical reactions mentioned above, it is also possible that an additional chemical reaction, the hydrolysis of $\mathrm{Sn}^{4+}$ occurs and forms precipitate $\mathrm{Sn}(\mathrm{OH})_{4}$ at the anode surface: ${ }^{42,49,53}$

$$
\mathrm{Sn}^{4+}+4 \mathrm{H}_{2} \mathrm{O} \rightarrow \mathrm{Sn}(\mathrm{OH})_{4}+4 \mathrm{H}^{+}
$$

Based on reactions (7), (8) and (10), the local $\mathrm{pH}$ on the anode surface will definitely decrease. Some investigations were performed to in situ inspect the localized $\mathrm{pH}$ distribution during the ECM. The $\mathrm{pH}$ at the regions close to anode changed to acidic

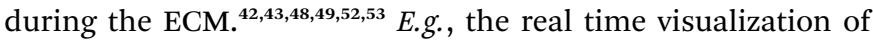
localized $\mathrm{pH}$ distribution at the anode and cathode surface using $\mathrm{pH}$ indicator during the ECM test of $\mathrm{Sn}$ is shown in Fig. $5 .^{53}$ It is seen that $\mathrm{pH}$ at the anode decreases over time as compared with the initial stage. Moreover, the acidic areas spread out with time (Fig. 5b-d).

\subsection{Reactions at the cathode}

The reduction of $\mathrm{O}_{2}$ as described in reaction (11) and the reduction of $\mathrm{H}_{2} \mathrm{O}$ as described in reaction (12) should be involved in the cathodic reactions during the ECM. $^{42,49,53,62,70,71,115}$

$$
\begin{aligned}
& \mathrm{O}_{2}+2 \mathrm{H}_{2} \mathrm{O}+4 \mathrm{e}^{-} \rightarrow 4 \mathrm{OH}^{-} \\
& 2 \mathrm{H}_{2} \mathrm{O}+2 \mathrm{e}^{-} \rightarrow \mathrm{H}_{2}+2 \mathrm{OH}^{-}
\end{aligned}
$$

The reduction of $\mathrm{O}_{2}$ consists of reduction of dissolved $\mathrm{O}_{2}$ in the electrolyte and the $\mathrm{O}_{2}$ diffused from the electrolyte/air interface. Investigation was performed to measure the cathodic polarization curves of Sn under thin electrolyte layer and found that water reduction dominated the corrosion process if the cathodic polarization potential is more negative than the potential for the water reduction. ${ }^{90}$ In electronics, the bias voltage applied across two electrodes may easily be as high as a few volts. This means the cathodic polarization potential applied at the cathode may often more negative than the potential of water reduction. Moreover, the concentration of oxygen including the dissolved oxygen and diffused oxygen is actually relatively low in the electrolyte layer. Therefore, the water reduction could be the main reaction under such conditions.

The most important cathodic reaction which is directly related to the ECM susceptibility should be the reduction of metal ions. Since $\mathrm{Sn}$ is usually the dominant element in the solder alloys, the reductions of $\mathrm{Sn}^{2+}$ and $\mathrm{Sn}^{4+}$ are definitely present at the cathode, as described by reactions (13) and (14).

$$
\begin{aligned}
& \mathrm{Sn}^{4+}+4 \mathrm{e}^{-} \rightarrow \mathrm{Sn} \\
& \mathrm{Sn}^{2+}+2 \mathrm{e}^{-} \rightarrow \mathrm{Sn}
\end{aligned}
$$

The reduction of alloy element metal ions may also be involved during the deposition.

In addition, in strong alkaline conditions the reduction of stannic complex may be involved in the cathodic reaction. This will be further discussed in detail in dendrites growth section.

\subsection{Precipitates formation}

The migration of the ions such as $\mathrm{Sn}^{4+}, \mathrm{Sn}^{2+}, \mathrm{M}^{n+}, \mathrm{OH}^{-}, \mathrm{H}^{+}$, etc. driven by electric field, diffusion and/or convection will occur 
Table 1 Summary of ECM studies of Sn and Sn solder alloys

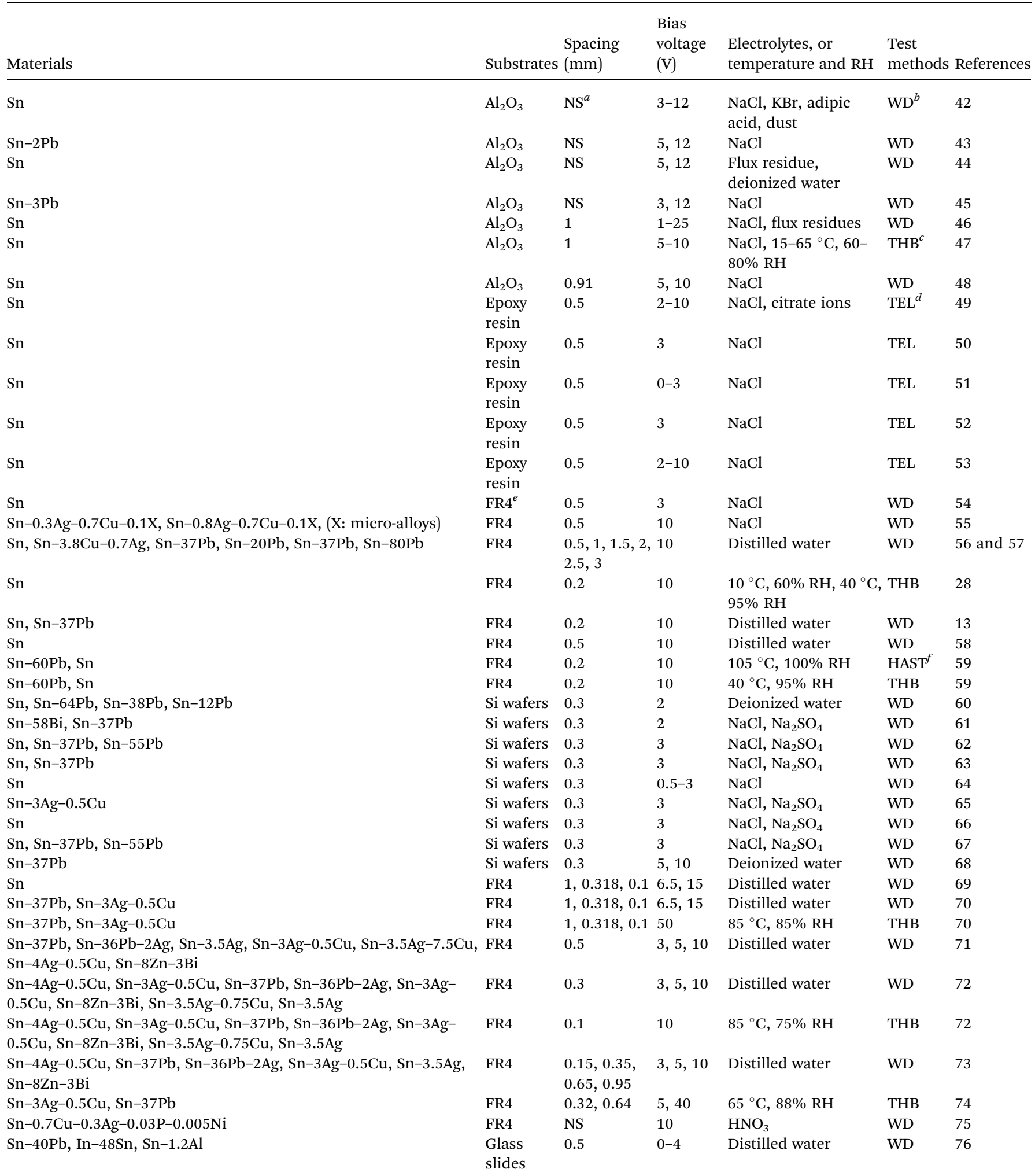

${ }^{a}$ Not specified. ${ }^{b}$ Water drop test. ${ }^{c}$ Thermal humidity bias test. ${ }^{d}$ Thin electrolyte layer test. ${ }^{e}$ Fiberglass reinforced epoxy (flame resistant-4).

${ }^{f}$ Highly accelerated stress test.

after their formation. During their migration, precipitates will be formed which mainly come from three types of possible reactions. On the one hand, precipitates $\mathrm{Sn}(\mathrm{OH})_{4}, \mathrm{Sn}(\mathrm{OH})_{2}$ and
$\mathrm{M}(\mathrm{OH})_{n}$ will be formed when $\mathrm{OH}^{-}$meets with $\mathrm{Sn}^{4+}, \mathrm{Sn}^{2+}$ and $\mathrm{M}^{n+}$ during their migration processes, respectively, as described in reactions (15)-(17). 

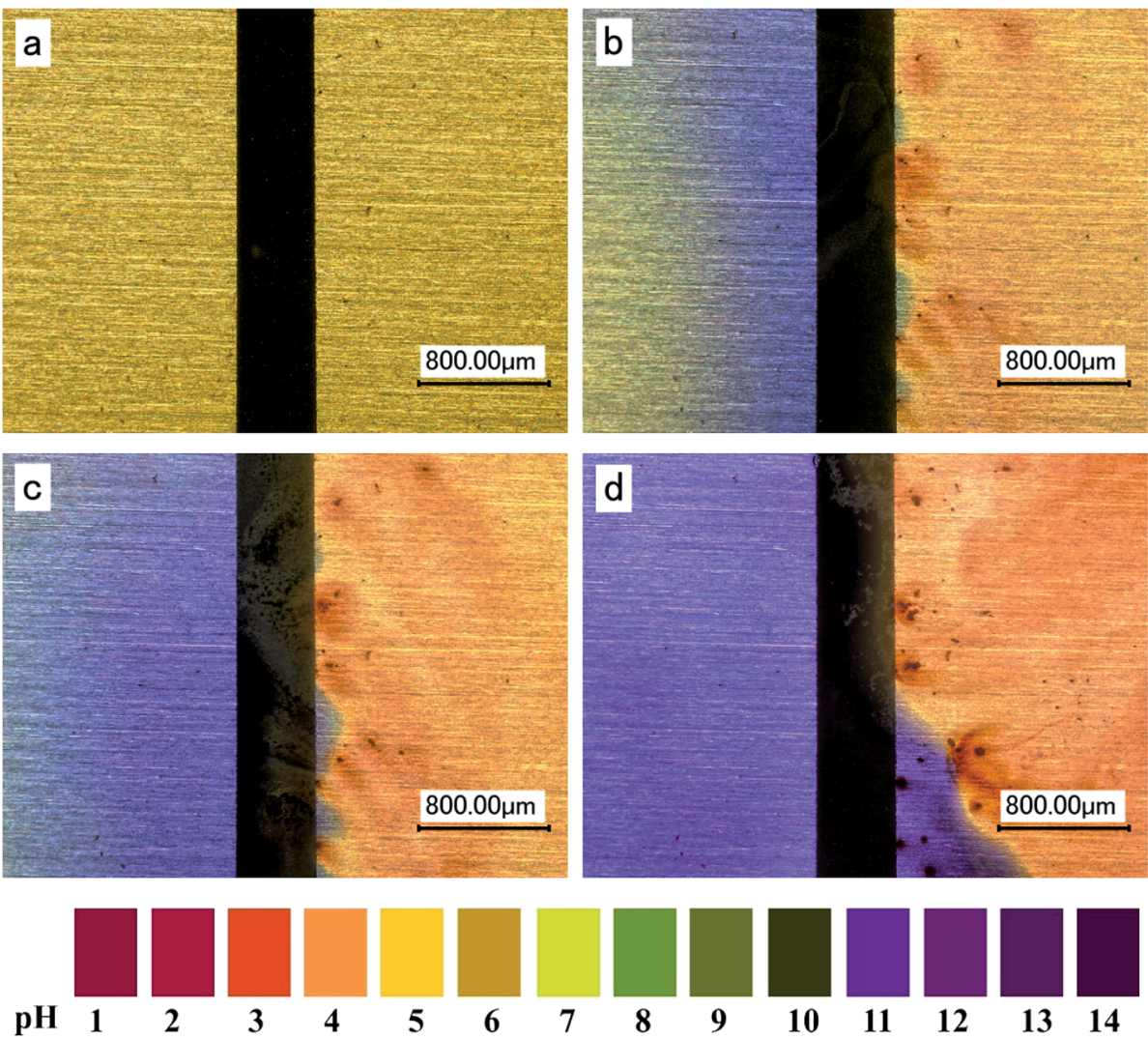

Fig. 5 Visualization of localized $\mathrm{pH}$ distribution on the both electrodes using $\mathrm{pH}$ indicator in electrolyte layer containing $1 \mathrm{mM}$ of chloride within a time interval of (a) 0 second, (b) 2 seconds, (c) 10 seconds and (d) 100 seconds (anode is on the right and cathode is on the left). Reproduced with permission from ref. 53. Copyright 2013, Elsevier.

$$
\begin{gathered}
\mathrm{Sn}^{4+}+4 \mathrm{OH}^{-} \rightarrow \mathrm{Sn}(\mathrm{OH})_{4} \\
\mathrm{Sn}^{2+}+2 \mathrm{OH}^{-} \rightarrow \mathrm{Sn}(\mathrm{OH})_{2} \\
\mathrm{M}^{n+}+n \mathrm{OH}^{-} \rightarrow \mathrm{M}(\mathrm{OH})_{n}
\end{gathered}
$$

These precipitates can be easily formed due to very low solubility product constants, as is summarized in Table $2 .^{\mathbf{1 1 6 - 1 1 8}}$

On the other hand, the direct oxidation of tin to $\mathrm{Sn}(\mathrm{OH})_{4}$ and the hydrolysis of $\mathrm{Sn}^{4+}$ as respectively described in reactions (7)

Table 2 The solubility product constants (at $25^{\circ} \mathrm{C}$ ) of the precipitates which may be present during the ECM of $\mathrm{Sn}$ and $\mathrm{Sn}$ solder alloys

\begin{tabular}{lll}
\hline Substances & $\begin{array}{l}\text { Solubility product } \\
\text { constant }\end{array}$ & References \\
\hline $\mathrm{Sn}(\mathrm{OH})_{2}$ & $5.45 \times 10^{-27}$ & 118 \\
$\mathrm{Sn}(\mathrm{OH})_{4}$ & $1.0 \times 10^{-57}$ & 117 \\
$\mathrm{AgCl}$ & $1.77 \times 10^{-10}$ & 118 \\
$\mathrm{Ag}_{2} \mathrm{SO}_{4}$ & $1.20 \times 10^{-5}$ & 118 \\
$\mathrm{CuCl}$ & $1.72 \times 10^{-7}$ & 118 \\
$\mathrm{Cu}(\mathrm{OH})_{2}$ & $5.0 \times 10^{-19}$ & 119 \\
$\mathrm{PbSO}$ & $2.53 \times 10^{-8}$ & 118 \\
$\mathrm{~Pb}(\mathrm{OH})_{2}$ & $1.43 \times 10^{-20}$ & 118 \\
$\mathrm{Zn}(\mathrm{OH})_{2}$ & $3.0 \times 10^{-17}$ & 118 \\
$\mathrm{Ni}(\mathrm{OH})_{2}$ & $5.48 \times 10^{-16}$ & 118
\end{tabular}

and (10) will also contribute to a part of the total amount of precipitates. The formed $\mathrm{Sn}(\mathrm{OH})_{4}$ and $\mathrm{Sn}(\mathrm{OH})_{2}$ can also be respectively dehydrated to $\mathrm{SnO}_{2}$ and $\mathrm{SnO}$ which are thermodynamically stable, as described by reactions (18) and (19). ${ }^{63,64,120,121}$

$$
\begin{gathered}
\mathrm{Sn}(\mathrm{OH})_{4} \rightarrow \mathrm{SnO}_{2}+2 \mathrm{H}_{2} \mathrm{O} \\
\mathrm{Sn}(\mathrm{OH})_{2} \rightarrow \mathrm{SnO}+\mathrm{H}_{2} \mathrm{O}
\end{gathered}
$$

It should be pointed out that amphoteric $\mathrm{Sn}(\mathrm{OH})_{4}$ can be dissolved in acidic media as stannic ions $\mathrm{Sn}^{4+}$ (reaction (20)) and in alkaline media as $\left[\mathrm{Sn}(\mathrm{OH})_{6}\right]^{2-}$ (reaction (21)). ${ }^{\mathbf{1 2 2}}$

$$
\begin{aligned}
& \mathrm{Sn}(\mathrm{OH})_{4}+4 \mathrm{H}^{+} \rightarrow \mathrm{Sn}^{4+}+4 \mathrm{H}_{2} \mathrm{O} \\
& \mathrm{Sn}(\mathrm{OH})_{4}+2 \mathrm{OH}^{-} \rightarrow\left[\mathrm{Sn}(\mathrm{OH})_{6}\right]^{2-}
\end{aligned}
$$

At last, other precipitates such as $\mathrm{SnCl}_{4}, \mathrm{AgCl}$ and $\mathrm{CuCl}_{2}$, $\mathrm{PbSO}_{4}$ may also be formed during the ECM process, ${ }^{118}$ depending upon the composition of solder alloys and the type of contaminants in the electrolyte layer.

The formation of precipitates remarkably affects the ion transport. Firstly, the formation of precipitates will consume metal ions before they reach the cathode. Thereby the concentration distribution of metals ions will be changed. Secondly, 
the formation of precipitates between cathode and anode will also hinder the movement of ions, thus it may even block the metal ions from reaching the cathode..$^{42,52,53}$ It is reported that the height of the formed precipitates could be measured by a 3D optical microscope. ${ }^{\mathbf{4 9 , 5 3}}$ E.g., Fig. 6 shows the 3D micrograph of electrodes for the ECM of Sn under $100 \mu \mathrm{m}$-thick electrolyte layers containing $17 \mathrm{mM}$ of chloride at bias voltage of $5 \mathrm{V.} .^{53}$ It is seen that the precipitates with a height of $162 \mu \mathrm{m}$ are formed after $3000 \mathrm{~s}$ between the anode and cathode when the electrolyte layer thickness is $100 \mu \mathrm{m}$. Accordingly, the precipitates can act as a wall-like barrier impeding the transport of ions due to the fact that the height of the accumulated precipitates is more than the thickness of the electrolyte layer.

\subsection{Dendrites growth}

The dendrites growth in ECM is essentially a kind of electrodeposition under non-uniform electric field. In acidic and weak alkaline environment, the dendrite growth of $\mathrm{Sn}$ and $\mathrm{Sn}$ solder alloys can be in general attributed to the reduction of metal ions as described in reactions (4), (13), and (14). However, in a strong alkaline environment, the reduction of some complex ions should also be taken into consideration. E.g., $\left[\mathrm{Sn}(\mathrm{OH})_{6}\right]^{2-}$ can be easily formed through reaction (21). As already mentioned above, $\left[\mathrm{Sn}(\mathrm{OH})_{6}\right]^{2-}$ can be reduced to metallic Sn, which is widely accepted in alkaline plating of tin, ${ }^{\mathbf{4 2 , 5 3 , 1 1 2}}$ as is described in reaction (22).

$$
\left[\mathrm{Sn}(\mathrm{OH})_{6}\right]^{2-}+4 \mathrm{e}^{-} \rightarrow \mathrm{Sn}+6 \mathrm{OH}^{-}
$$

Although it will be repelled by the cathode since $\left[\mathrm{Sn}(\mathrm{OH})_{6}\right]^{2-}$ is inherently negatively charged, here the movement of $\left[\mathrm{Sn}(\mathrm{OH})_{6}\right]^{2-}$ to reach the cathode could be driven by diffusion and/or convection. ${ }^{43,53,112}$
As soon as the dendrite reaches the anode, the short circuit occurs and causes the failure of electronics. The morphologies of dendrites of Sn and Sn solder alloys vary from needle-like, tree-like and powder-like, which strongly depend on the path of current flow and the concentrations of species involved in the electrolytic process. ${ }^{107,108}$ It is interesting that Dominkovics and Harsányi $^{56,57}$ reported that a fractal description of the morphology could be used to analyze the dendrites growth of Sn and Sn solder alloys. Most importantly, the fractal dimensions of dendrites formed during ECM could be used in failure analysis in "first and fast" identification of critical metallic elements without the application of chemical micro-analytical methods.

\section{Effect of alloy elements}

\section{1. $\mathrm{Pb}$}

With a melting temperature of $183^{\circ} \mathrm{C}$, the eutectic $\mathrm{Sn}-\mathrm{Pb}$ solder alloys allow soldering conditions that are compatible with most substrate materials and devices. ${ }^{\mathbf{1 2 3 , 1 2 4}}$ As one of the primary components of eutectic solders, $\mathrm{Pb}$ provides many technical advantages such as (i) reduces the surface tension of pure tin, ${ }^{125}$ (ii) prevents the transformation of white tin to gray tin, ${ }^{\mathbf{1 2 6}}$ and (iii) serves as a solvent metal. ${ }^{124}$ Therefore, $\mathrm{Sn}-\mathrm{Pb}$ solder alloys were widely used in electronics industry. Although the restriction of hazardous substances (RoHS) effectively bans the use of $\mathrm{Pb}$ in electrical products, there is still exemption for some special $\mathrm{Sn}-\mathrm{Pb}$ solders such as high-Pb solders (contain $85 \%$ by weight or more $\mathrm{Pb}$ ) which are broadly used in automotive, space, oil and gas, and avionics industries. ${ }^{127,128}$ So the ECM of $\mathrm{Sn}-\mathrm{Pb}$ solder alloys still deserves further study.

The ECM behaviors of $\mathrm{Sn}-\mathrm{Pb}$ alloys with different $\mathrm{Pb}$ contents are strongly related to the migration environment. According to the literature, three main environments were used

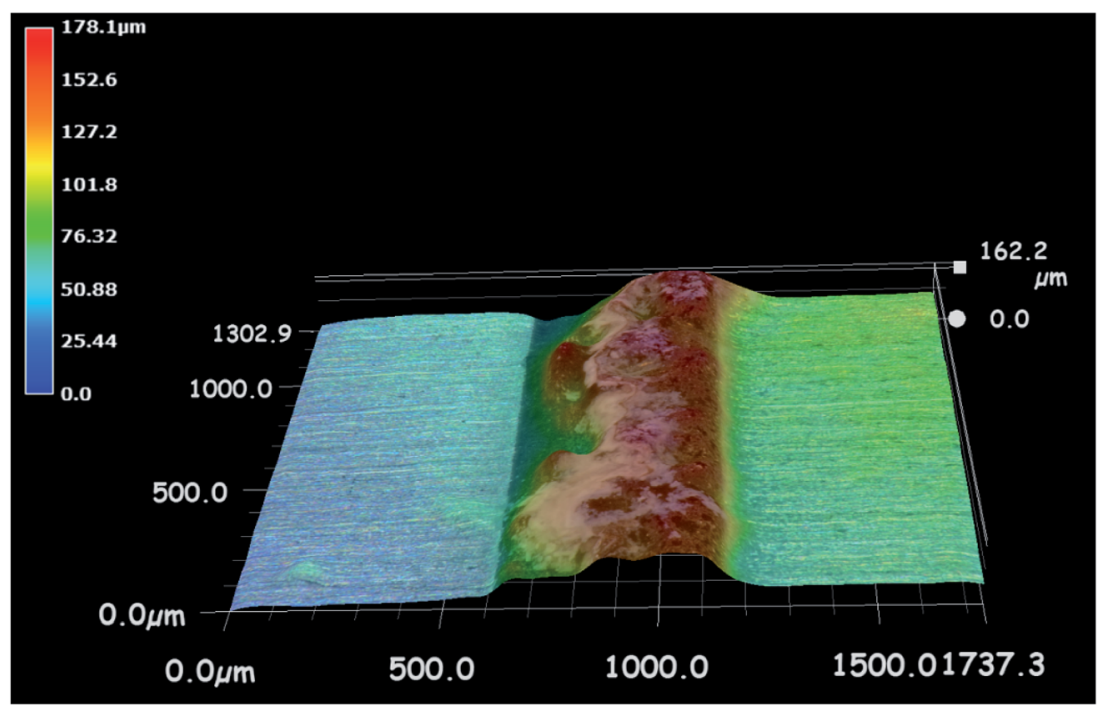

Fig. 6 3D micrograph of precipitates formed during the ECM of tin under $100 \mu \mathrm{m}$-thick electrolyte layer containing $1.7 \times 10^{-2} \mathrm{M}$ of chloride at bias voltage of $5 \mathrm{~V}$. The height of the precipitates barrier is about $162 \mu \mathrm{m}$ (anode is on the right and cathode is on the left). Reproduced with permission from ref. 53. Copyright 2013, Elsevier. 
including pure water or distilled water ${ }^{78,81}$ chloride-containing solution ${ }^{60-64,67,68}$ and sulfate-containing containing solution. ${ }^{61-63,67}$ It can be summarized that the time-to-failure which is proportional to the ECM resistance of $\mathrm{Sn}-\mathrm{Pb}$ solder alloys decreases with increasing $\mathrm{Pb}$ content in a pure water or chloride-containing solution, whereas it increases with increasing $\mathrm{Pb}$ content in sulfate-containing solution. A few examples are given below.

Yu et al. ${ }^{71}$ compared the ECM behaviors between $\mathrm{Sn}-37 \mathrm{~Pb}$ solder alloy and $\mathrm{Sn}-36 \mathrm{~Pb}-2 \mathrm{Ag}$ solder alloy in distilled water. They concluded that the main migration element was $\mathrm{Pb}$. Takemoto et al. ${ }^{76}$ reported that in pure water pure $\mathrm{Pb}$ showed the highest susceptibility of ECM, thereby the addition of $\mathrm{Pb}$ increased the susceptibility, and Sn had the lowest susceptibility compared to that of $\mathrm{Pb}$ and $\mathrm{Sn}-40 \mathrm{~Pb}$ solder alloy. Lee et al. ${ }^{82}$ investigated the ECM characteristic of $\mathrm{Sn}-\mathrm{Pb}$ solder alloys with varying DC bias voltages under $85{ }^{\circ} \mathrm{C}$ and $85 \% \mathrm{RH}$ condition. They found that $\mathrm{Pb}$ was more susceptible to ECM failure than $\mathrm{Sn}$ in the eutectic $\mathrm{Sn}-\mathrm{Pb}$ solder alloys.

The ECM phenomenon of $\mathrm{Sn}-\mathrm{Pb}$ solder alloys containing different $\mathrm{Pb}$ contents in chloride-containing solution is similar to that in pure water. Lee et al. ${ }^{60,63,64}$ studied time-to-failure of the pure $\mathrm{Sn}, \mathrm{Pb}$ and $\mathrm{Sn}-\mathrm{Pb}$ solder alloys in $0.001 \mathrm{wt} \% \mathrm{NaCl}$ solution using water drop test. The representative results were shown in Fig. $7 .{ }^{60}$ It was found that the time-to-failure increased with decreasing $\mathrm{Pb}$ content, and pure $\mathrm{Pb}$ showed the shortest time-to-failure. This was ascribed to that a passive layer on $\mathrm{Sn}$ surface could be formed in $\mathrm{NaCl}$ solution, but not for $\mathrm{Pb}$. Yoo et $a .^{62,67}$ also found that the time-to-failure of $\mathrm{Sn}-\mathrm{Pb}$ solder alloys decreased with increasing $\mathrm{Pb}$ content in chloridecontaining solution.

Lee et al. and Yoo et al. ${ }^{60-62,67}$ performed respectively a series of ECM experiments of $\mathrm{Pb}, \mathrm{Sn}$ and $\mathrm{Sn}-\mathrm{Pb}$ solder alloys in sulfate-containing solution. They found that the time-to-failure increased with increasing $\mathrm{Pb}$ content, indicating that the addition of $\mathrm{Pb}$ increased the ECM resistance of $\mathrm{Sn}-\mathrm{Pb}$ solder alloys in sulfate-containing solution. This is a reverse

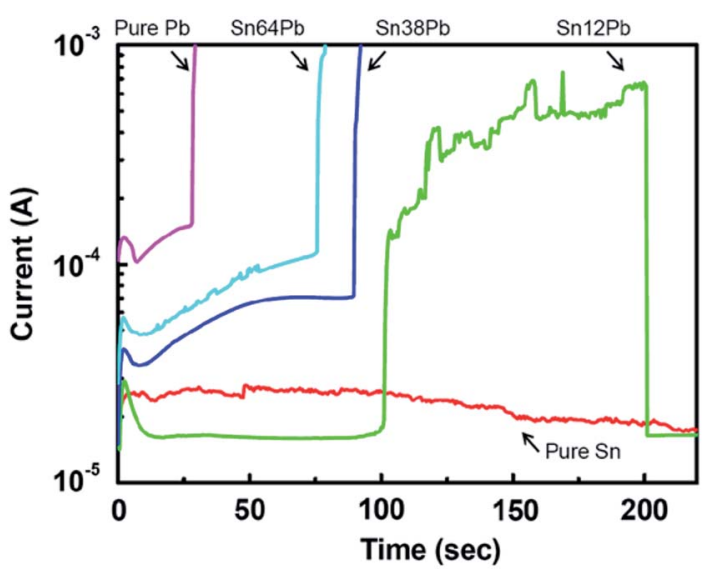

Fig. 7 In situ current-time relationship and insulation failure during water drop test while applying $2 \mathrm{~V}$ in $0.001 \mathrm{wt} \% \mathrm{NaCl}$ solution at room temperature with respect to alloy composition of $\mathrm{Sn}-\mathrm{Pb}$ solders. Reproduced with permission from ref. 60. Copyright 2011, Springer. phenomenon in contrast to that in chloride-containing solution and pure water. It was believed that $\mathrm{Pb}$ was protected from corrosion attack in sulfate by forming an insoluble layer of $\mathrm{PbSO}_{4}$ or $\mathrm{PbO}^{63}$ The extremely low solubility of $\mathrm{PbSO}_{4}$ (see Table 2) and the insoluble property of $\mathrm{PbO}$ are favorable for the formation of an insoluble layer on the solder alloys surface.

\section{2. $\mathrm{Ag}$}

$\mathrm{Sn}-\mathrm{Ag}$ solder alloys have been considered strong candidates to replace the $\mathrm{Sn}-\mathrm{Pb}$ solder alloys because of two main reasons. On the one hand, their properties are reasonably compatible with those of the $\mathrm{Sn}-\mathrm{Pb}$ solder alloys, ${ }^{129,130}$ and on the other hand, they have better mechanical properties (ductility, creep resistance and thermal resistance) than the $\mathrm{Sn}-\mathrm{Pb}$ solder alloys. ${ }^{131}$ The eutectic composition for the $\mathrm{Sn}-\mathrm{Ag}$ binary system occurs at $\mathrm{Sn}-3.5 \mathrm{Ag}$. The eutectic temperature is $221{ }^{\circ} \mathrm{C}$.

The addition of Ag into Sn matrix can form a chemical stable intermetallic compound $\mathrm{Ag}_{3} \mathrm{Sn}$, in which $\mathrm{Ag}$ is difficult to escape during the ECM, resulting in that $\mathrm{Ag}$ migration is prevented. Therefore, it is generally considered that the migration characteristics of $\mathrm{Sn}-\mathrm{Ag}$ solder alloys are still related to the dissolution characteristics of $\mathrm{Sn},{ }^{27,65,71,132}$ although that pure $\mathrm{Ag}$ is one of the most susceptible metals to ECM. ${ }^{24}$

Yoo et al. ${ }^{27}$ evaluated the ECM susceptibility of Sn, Sn-3.5Ag and $\mathrm{Sn}-3 \mathrm{Ag}-0.5 \mathrm{Cu}$ solder alloys in $0.001 \mathrm{wt} \% \mathrm{Na}_{2} \mathrm{SO}_{4}$ at room temperature. They found that $\mathrm{Ag}$ addition increased the time-tofailure of solder alloys and the dendrite was mainly composed of Sn regardless of the solder alloys. It was attributed to that the addition of Ag improved the passivation behavior and pitting corrosion resistance and formed inert intermetallic compounds, thus, the dissolution of Ag was suppressed and only Sn was dissolved. Tanaka et al. ${ }^{132}$ also reported that in Sn3.5Ag solder alloys, $\mathrm{Ag}$ combines with $\mathrm{Sn}$ to form a stable compound $\mathrm{Ag}_{3} \mathrm{Sn}$ that did not dissolve during ECM, and therefore the migration resistance of $\mathrm{Sn}-\mathrm{Ag}$ solder alloys was related to the dissolution characteristics of Sn. Yu et al. ${ }^{71}$ found that the main element was $\mathrm{Pb}$ for the ECM of $\mathrm{Sn}-37 \mathrm{~Pb}$ and $\mathrm{Sn}-$ $36 \mathrm{~Pb}-2 \mathrm{Ag}$ solder alloys in distilled water. While for $\mathrm{Sn}-\mathrm{Ag}$ and $\mathrm{Sn}-\mathrm{Ag}-\mathrm{Cu}$ solder alloys, $\mathrm{Sn}$ led the migration. Similarly, He et al. ${ }^{74}$ also reported that in the ECM of $\mathrm{Sn}-3 \mathrm{Ag}-0.5 \mathrm{Cu}$ solder alloy, Sn always dominated composition of dendrites and $\mathrm{Ag}$ migrated only occasionally. Jung et al. ${ }^{65}$ even thought that $\mathrm{Ag}$ did not take part in ECM of Sn-3Ag-0.5Cu in $\mathrm{NaCl}$ and $\mathrm{Na}_{2} \mathrm{SO}_{4}$, and they believed that $\mathrm{Sn}$ was the only element that contributed to ECM of $\mathrm{Sn}-3 \mathrm{Ag}-0.5 \mathrm{Cu}$ solder alloy. These results demonstrate that the ECM of $\mathrm{Sn}-\mathrm{Ag}$ solder alloys is still determined by $\mathrm{Sn}$, but not Ag. Additionally, Medgyes et al. ${ }^{133}$ found that $\mathrm{Sn}-$ $0.8 \mathrm{Ag}-0.7 \mathrm{Cu}$ solder alloy had a lower resistance against ECM than $\mathrm{Sn}-0.3 \mathrm{Ag}-0.7 \mathrm{Cu}$. This was attributed to that $\mathrm{Sn}-0.8 \mathrm{Ag}-$ $0.7 \mathrm{Cu}$ solder alloy had a significantly higher corrosion rate than the $\mathrm{Sn}-0.3 \mathrm{Ag}-0.7 \mathrm{Cu}$, since the formed inhomogeneous $\mathrm{SnO}_{x}$ was located significantly deeper in case of $\mathrm{Sn}-0.8 \mathrm{Ag}-0.7 \mathrm{Cu}$.

\section{3. $\mathrm{Cu}$}

$\mathrm{Sn}-\mathrm{Cu}$ solder alloy is also one of the available alternatives of $\mathrm{Sn}-$ $\mathrm{Pb}$ solder alloy. The $\mathrm{Sn}-\mathrm{Cu}$ binary alloy has a eutectic 
composition of $\mathrm{Sn}-0.7 \mathrm{Cu}$ with a melting temperature of $227{ }^{\circ} \mathrm{C} .{ }^{114}$ As the addition of $\mathrm{Ag}$ into $\mathrm{Sn}$, the addition of $\mathrm{Cu}$ into $\mathrm{Sn}$ matrix causes the formation of an intermetallic compound $\mathrm{Sn}_{6} \mathrm{Cu}_{5}$ which is also chemical stable. ${ }^{27}$ Therefore, the effect of $\mathrm{Cu}$ addition on the ECM of Sn solder alloys is very similar to $\mathrm{Ag}$ addition.

Yoo et al. ${ }^{27}$ reported that $\mathrm{Cu}$ could improve the passivation behavior and pitting corrosion resistance of $\mathrm{Sn}$ based solder alloys. Most importantly, the dissolution of Cu during the ECM was suppressed because of the formation of the inert intermetallic compounds $\mathrm{Sn}_{6} \mathrm{Cu}_{5}$. He et al. ${ }^{74}$ evaluated the ECM behavior of $\mathrm{Sn}-3 \mathrm{Ag}-0.5 \mathrm{Cu}$ solder alloy under a condition of $88 \%$ relative humidity at $65{ }^{\circ} \mathrm{C}$. They found that in the dendrites, $\mathrm{Sn}$ was dominated and $\mathrm{Cu}$ was a minor constituent. Yu et al. ${ }^{71}$ studied the ECM of a series of $\mathrm{Sn}-\mathrm{Ag}-\mathrm{Cu}$ solder alloys in distilled water using water drop test. They found Sn led the migration and $\mathrm{Cu}$ had a small susceptibility due to the formation of intermetallic compounds in alloys. All these studies indicate that $\mathrm{Cu}$ addition can improve the ECM resistance of $\mathrm{Sn}$ solder alloys to some extent. However, it is worthy to note that pure $\mathrm{Cu}$ may take part in the ECM of Sn solder alloys if a $\mathrm{Cu}$ substrate is used in the ECM test. This is due to that the poor wettability of solder paste leads to part exposure of Cu substrate at the wetting brim. ${ }^{72}$

\section{4. $\mathrm{Zn}$}

The $\mathrm{Sn}-\mathrm{Zn}$ solder alloy also appears to be an attractive alternative for $\mathrm{Sn}-\mathrm{Pb}$ solder alloys. $\mathrm{Sn}-9 \mathrm{Zn}$ is the eutectic composition for the $\mathrm{Sn}-\mathrm{Zn}$ system, with a melting temperature of $198{ }^{\circ} \mathrm{C}$ that is relatively close to eutectic $\mathrm{Sn}-\mathrm{Pb}$ alloys. ${ }^{124} \mathrm{~A}$ few studies have been conducted on ECM of Sn-Zn solder alloys. However, there are still some inconsistencies among these ref. 72, 132 and 134 regarding the role of $\mathrm{Zn}$ in ECM of $\mathrm{Sn}-\mathrm{Zn}$ alloys.

Yu et al. ${ }^{72}$ investigated the ECM of Sn-8Zn-3Bi solder alloy in distilled water using water drop test. They found that it was always $\mathrm{Zn}$ to migrate, which means the alloying with $\mathrm{Zn}$ in solder alloy has a higher susceptibility to ECM. Hua et al. ${ }^{\mathbf{1 3 4}}$ compared the ECM behavior of $\mathrm{Sn}-35 \mathrm{Bi}-1 \mathrm{Ag}$ solder alloy with and without $\mathrm{Zn}$ doping at $80{ }^{\circ} \mathrm{C}$ and $85 \% \mathrm{RH}$. It was found that $\mathrm{Zn}$ doping reduced the time-to-failure from 240 hours to 100 hours, indicating that $\mathrm{Zn}$ addition decreased the ECM resistance of Sn solder alloy. However, Tanaka ${ }^{132}$ reported that in the ECM of Sn-9Zn solder alloy, Sn still dominated the migration process, because $\mathrm{Zn}$ and $\mathrm{Sn}$ formed a passive film that suppressed the dissolution of $\mathrm{Zn}$. Therefore, a further and systematic work regarding the effect of $\mathrm{Zn}$ addition on $\mathrm{Sn}-\mathrm{Zn}$ solder alloys is needed.

\subsection{Other elements}

Other elements such as $\mathrm{Bi}$, In and $\mathrm{Sb}$ could also be added into Sn matrix to form some specific solder alloys. E.g., due to the substantially lower melting temperature and a much lower tendency to scavenge gold, compared to $\mathrm{Sn}-\mathrm{Pb}$ solder alloys, Sn-In solder alloys have been used for surface mounting technology applications. ${ }^{\mathbf{1 2 4}}$ However, studies on ECM of these solder alloys are very limited. Three examples are given below.
Tanaka $^{\mathbf{1 3 2}}$ found that $\mathrm{Sn}-58 \mathrm{Bi}$ solder alloy revealed sections of segregated Bi surface remaining and selective dissolution of Sn during the migration test. It was therefore assumed that SnBi solder alloy suppressed anodic dissolution more than such materials as Sn alone or Sn-3.5Ag solder alloy. Takemoto et al. ${ }^{76}$ investigated the pure In and In-48Sn in distilled water. It was found that pure In and In-48Sn solder alloys were immune to ECM in pure water. Medgyes et al. ${ }^{55}$ used the transmission electron microscopy to detect the composition of dendrites which were formed during the ECM of Sn solder alloys with a low level of Ag. Sb was found in the dendrites, indicating that $\mathrm{Sb}$ also took part in the ECM of solder alloy process.

\section{Effect of contaminants}

Surface contaminants, especially hygroscopic types have a significant influence on the overall ECM process. The effects of contaminants on the ECM of Sn and Sn solder alloys have been extensively investigated in various research works where contaminants such as chlorides, sulfates and flux residues are mainly involved.

\subsection{Chlorides}

Many studies about contaminants in ECM of Sn and Sn solder alloys focused on the chlorides since chloride is a common contaminant on device surfaces coming from environment. Chlorides in electronic devices may be originated from human sweat and fingerprints, dust in the air, the flux residues from the manufacturing process, the degradation of package, and even the salt spray from the seas. ${ }^{77}$ For the automotive electronics the chlorides is also easily originated from the deicing agents on the roadway. ${ }^{\mathbf{1 3 5}}$ Chlorides have a rather complicated effect on the ECM of Sn and Sn solder alloys, because they significantly affect every step of ECM of Sn and Sn solder alloys.

Chlorides can accelerate the electrolyte layer formation because of their hygroscopic properties. As already mentioned above, the electrolyte layer formation depends on the critical relative humidity, above which the condensation starts to take place. The critical relative humidity corresponds to the equilibrium relative humidity above the saturated salt solutions. ${ }^{77}$ The presence of chlorides can apparently decrease the equilibrium relative humidity. For example, Greenspan ${ }^{136}$ reported that at $25{ }^{\circ} \mathrm{C}$, the equilibrium relative humidity is about $84 \%$ for $\mathrm{KCl}$, $75 \%$ for $\mathrm{NaCl}, 33 \%$ for $\mathrm{MgCl}_{2}$ and only $11 \%$ for $\mathrm{LiCl}$. Therefore, the electrolyte layer formation with the chlorides on the sample surface will be much more easily than that in the absence of chlorides.

The anodic dissolution of $\mathrm{Sn}$ and $\mathrm{Sn}$ solder alloys is also significantly affected by chlorides. On the one hand, the presence of chlorides definitely increases the conductivity of the electrolyte formed by condensation. Thus they increase the overall speed of the ECM process where the anodic dissolution is first involved. On the other hand, chloride ions are oxidized on the surface of the anode during the ECM and they leave the electrolyte forming $\mathrm{Cl}_{2}$ gas, ${ }^{53}$ but they may also form chlorine oxide and/or chlorous acid destroying the existing oxide film on 
the anode surface or inhibiting its formation which prevents the anode to have a passive film on the surface. ${ }^{77}$ Consequently, the anodic dissolution of Sn and Sn solder alloys is speeded.

More precipitates could be formed during the ECM of Sn and Sn solder alloys in the presence chlorides. According to reactions at the electrodes, in the presence of chlorides more amounts of metal ions and hydroxyl ions will be formed than that in the absence of chlorides, because both the anodic and cathodic reaction rates are increased. Therefore, more hydroxide such as $\operatorname{Sn}\left(\mathrm{OH}_{4}\right)$ and/or oxides precipitates such as $\mathrm{SnO}_{2}$ can be formed during the ion migration. Additionally, chloride ions can also form precipitates with metal ions, for example $\mathrm{AgCl}, \mathrm{CuCl}_{2}$, etc. ${ }^{118}$

The increasing amount of precipitates due to the presence of chlorides will not only hinder the ion migration, but also act against the dendrite growth because the fewer metal ions can reach the cathode to be deposited. Minzari et al. ${ }^{42}$ studied the ECM of Sn using the water drop test with sodium chloride concentration up to $1000 \mathrm{ppm}$. They found that the probability of dendrite growth decreased when the chloride concentration was beyond a certain level. Furthermore, no dendrite was observed when the chloride concentration reached to $1000 \mathrm{ppm}$. Verdingovas et al. ${ }^{46}$ reported that the ECM probability of Sn in sodium chloride solution had a peak value and the migration probability tended to decrease with increase in concentration above this peak value. Zhong et al. ${ }^{52}$ studied the ECM of Sn under thin electrolyte layers with different chloride concentrations (see Fig. 8).

It was found that in low chloride concentration, dendrite coexisted with precipitates. In intermediate chloride concentration, there were only precipitates but no dendrite because the precipitates acted as a spatial barrier, hindering the ions migration and against the dendrite growth. In high chloride concentration, the higher $\mathrm{OH}^{-}$concentration presented, resulting in the dissolution of $\mathrm{Sn}(\mathrm{OH})_{4}$ to form $\left[\mathrm{Sn}(\mathrm{OH})_{6}\right]^{2-}$. Then, the dendrite grew again by the reduction of $\left[\mathrm{Sn}(\mathrm{OH})_{6}\right]^{2-}$. In addition, the chloride ions concentration also affects the degree of uniformity of the electric field on the surface of electrode. High concentration of chloride ions in general increases the degree of uniformity of the electric field. Thus, it was found that a continuous process of deposition on the whole surface of cathode replaced the dendritic growth process at high $\mathrm{Cl}^{-}$concentrations. ${ }^{53,77}$

\subsection{Sulfates}

Sulfates are also one of the contaminants coming from environment. Like the chlorides, sulfates can also decrease the critical relative humidity and thereby accelerate the electrolyte formation. Moreover, the conductivity of the electrolyte and the initial reaction rate during the ECM of Sn and Sn solder alloys also increase in the presence of sulfates. The effect of sulfates on the ECM of Sn and Sn solder alloys are mainly determined by the passive film or oxide film formed on the sample in $\mathrm{Na}_{2} \mathrm{SO}_{4}$ containing electrolyte. ${ }^{61-63,66,67}$

The presence of sulfates can affect the ability of protective film formed on Sn and Sn solder alloys. The presence of sulfates can increase stability of surface oxide film on $\mathrm{Sn}-\mathrm{Pb}$ solder alloys because of the formation of a protective $\mathrm{PbSO}_{4}$ and $\mathrm{Pb}$ oxides film. The time-to-failure of $\mathrm{Sn}-\mathrm{Pb}$ solder alloys increased with increasing $\mathrm{Pb}$ content. ${ }^{67}$ However, Jung et al. ${ }^{66}$ found that
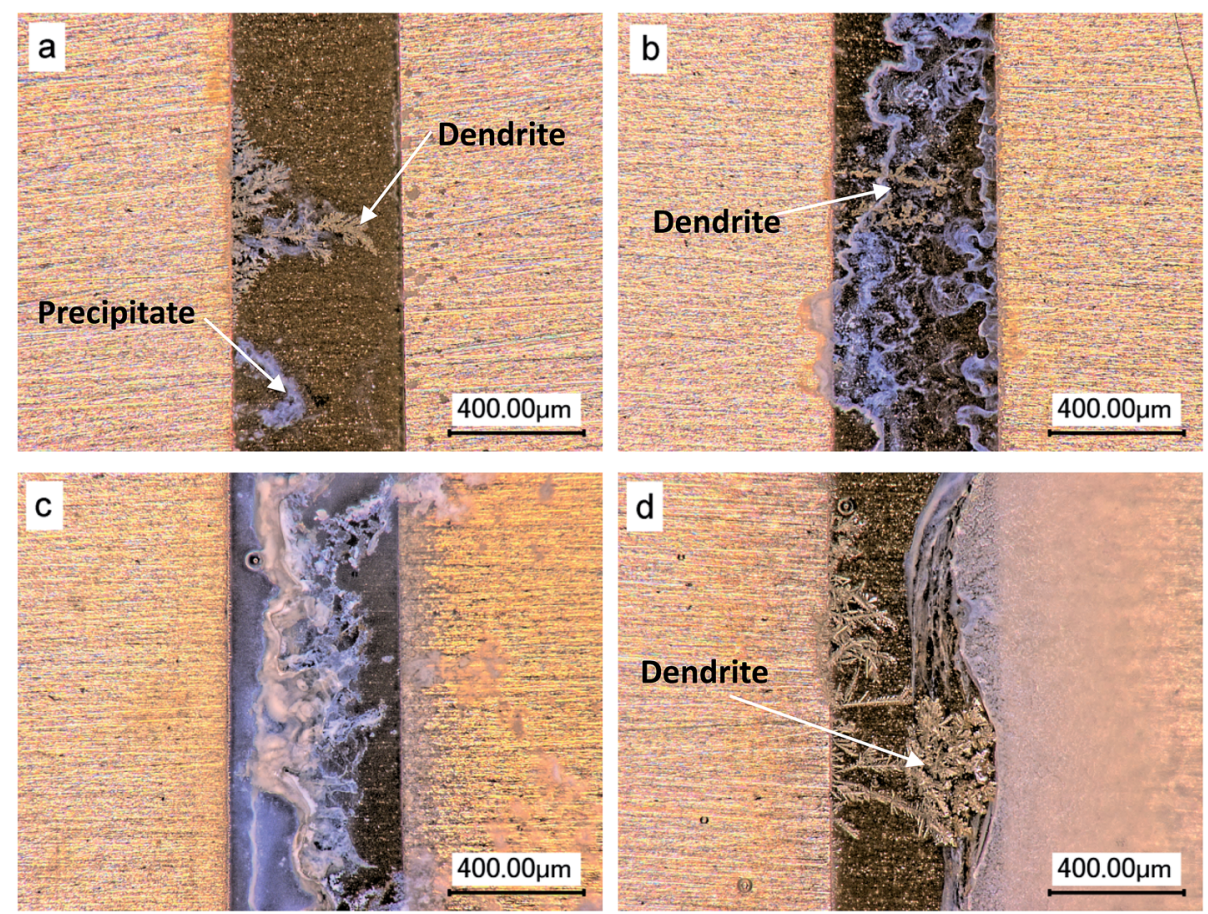

Fig. 8 Optical micrographs of ECM of tin under $100 \mu \mathrm{m}$ electrolyte layer with various chloride concentrations at $3 \mathrm{~V}$ of bias: (a) $0.1 \mathrm{mM}$, (b) $5 \mathrm{mM}$, (c) $10 \mathrm{mM}$ and (d) $500 \mathrm{mM}$ (anode is on the right and cathode is on the left). Reproduced with permission from ref. 52. Copyright 2013, Elsevier. 
the time-to-failure of $\mathrm{Sn}$ in $\mathrm{NaCl}$ solution was longer than that in $\mathrm{Na}_{2} \mathrm{SO}_{4}$ solution. Moreover, the pitting potential of $\mathrm{Sn}$ in $\mathrm{NaCl}$ solution was also higher than that in $\mathrm{Na}_{2} \mathrm{SO}_{4}$ solution. They explained that this was attributed to that passive film formed on pure $\mathrm{Sn}$ during the water drop tests in $\mathrm{NaCl}$ solution was more stable than that formed in $\mathrm{Na}_{2} \mathrm{SO}_{4}$ solution. A similar phenomenon was also found for $\mathrm{Sn}-3 \mathrm{Ag}-0.5 \mathrm{Cu}$ solder alloy in $\mathrm{Na}_{2} \mathrm{SO}_{4}$ solution where the passive film is thinner than that formed in $\mathrm{NaCl}$ solution. ${ }^{66}$

\subsection{Flux residues}

Flux residues are usually corrosive and favorable for some steps of ECM because they are usually composed of ionic substances ${ }^{4,46,137-146}$ and other species. The most common ionic substances in flux residues are weak organic acids, or halogenides such as chlorides. Both of them will not only promote the condensation process due to their hygroscopic property, but also increase the conductivity of a condensed water layer.

One or more of the short-chain weak organic acids such as adipic acid, glutaric acid, succinic acid, malic acid or formic acid are often contained in the flux residues when a no-clean flux is used. ${ }^{44}$ It is well known that a short-chain weak organic acid dissolved into the water can be partially dissociated to ionic species which result in an increase in conductivity of electrolyte layer and a decrease in solution $\mathrm{pH}$. Furthermore, weak organic acids also show hygroscopic properties, although different acids have different hygroscopic properties. ${ }^{\mathbf{1 3 8 , 1 4 5}}$ It was generally considered that high concentration of weak organic acids can suppress the ECM of Sn and Sn solder alloys. However, small inconsistencies in the explanation of mechanisms still exist. A few examples are given below.

Minzari et $a .^{\mathbf{4 2}}$ studied the effect of adipic acid on the ECM of Sn under water drop where the adipic acid concentration was ranged from $1 \mathrm{ppm}$ (by weight) to saturated condition. It was found that the probability of $\mathrm{Sn}$ migration decreased with increasing adipic acid concentration. This effect was attributed to two factors. On the one hand, the presence of adipic acid with a significant amount could act as acidic buffer which was more suitable for precipitation formation rather than dendrite growth. On the other hand, this effect was related to the passivation of anode surface caused by organic compounds, so that anodic dissolution was decreased.

Verdingovas et al. $^{46}$ investigated the ECM of $\mathrm{Sn}$ in flux residues using the water drop test. The flux residues came from the no-clean organic acid based wave solder flux where adipic was used as activator and synthetic resin was used as the film former. They found that there was a peak value of ECM probability at a critical concentration of flux residues (at $92 \mu \mathrm{g} \mathrm{cm}^{-2}$ ) and the probability of migration was reduced at both below and above this critical concentration. It was considered that at low concentration the behavior was assumed to be due to the low dissolution of metal ions, while at high concentration the effect was due to over production of metal ions thereby precipitation of tin hydroxide dominated.

Ambat et $a l .{ }^{44}$ studied the effect of flux residue formed at room temperature and at $235{ }^{\circ} \mathrm{C}$ using water drop test. The main organic acid in this flux residue was also adipic acid. They found that among the samples with the flux residue formed under both conditions, only one of them showed the migration, while others did not although strong electrochemical reactions such as gas evolution was evident at the electrode at least initially. It was attributed to that acid component might be acting as an anodic inhibitor reducing the metal dissolution and thereby the dendrite growth was stopped.

Zhan et al. $^{84}$ compared the ECM behaviors of $\mathrm{Sn}-37 \mathrm{~Pb}$ with rosin-based flux and with aqueous-based flux. It was found that residues of rosin-based flux contained about 50 wt $\%$ higher concentration of weak organic acids than aqueous-based flux after reflow. This led to higher activity and promoted moisture adsorption, further reducing the time-to-failure due to the reduction of surface insulation resistance.

Tanaka et al. ${ }^{144}$ investigated the effect of flux residue on the ECM of Pb-free solder alloys including Sn-3.5Ag, Sn-9Zn, Sn$5 \mathrm{Bi}, \mathrm{Sn}-0.8 \mathrm{Cu}$ and $\mathrm{Sn}-37 \mathrm{~Pb}$ solder alloys. The samples were first solder-plated, then coated with flux, and finally heat-treated using reflow processing conditions. The flux consisted of 10 $\mathrm{wt} \%$ rosin and $0.01 \mathrm{wt} \%$ activator (halogen and organic acids, the exact concentration was unknown). It was found that the presence of flux residue suppressed anodic dissolution and effectively prevented the occurrence of migration. However, with $\mathrm{Sn}-9 \mathrm{Zn}$, the flux components such as halogen and organic acids could react with $\mathrm{Zn}$ and form a new compound layer between flux and substrate. This compound layer decreased the adhesion between flux film and substrate, subsequently, speeded the migration.

The effect of chlorides in flux residues on ECM of Sn and Sn solder alloys can be seen in chlorides section. In addition, a resin component is often contained in the flux residues. This component can easily attract dust during operation, which will eventually make surfaces hydrophilic and thus become a potential source for ions. ${ }^{137}$

\subsection{Other contaminants}

Other contaminants such as bromide ion, ${ }^{\mathbf{4 2}}$ dust, ${ }^{\mathbf{4 2 , 4 4}}$ and $\mathrm{H}_{2} \mathrm{~S}^{\mathbf{1 4 7}}$ have also been investigated in the ECM of $\mathrm{Sn}$ or $\mathrm{Sn}$ solder alloys.

A tendency of ECM in bromide is similar to the chloride, where higher concentration of bromide reduces the dendrite formation probability. ${ }^{42}$ The component and amount of dust depend on where the dust was collected. Different ECM behaviors may be present when the dust is collected from different environments. For example, Minzari et $a .^{\mathbf{4 2}}$ compared the effects on ECM of Sn which was exposed in a mild dust and an aggressive dust for two months, respectively. The mild dust was collected indoor in household and the aggressive dust was collected in a pig farm. It was found that only the presence of mild dust at low levels resulted in ECM. Zou et al. ${ }^{147}$ studied the ECM of Sn-37Pb solder alloy in trace amount ( $1 \mathrm{ppm}$ ) of $\mathrm{H}_{2} \mathrm{~S}$ condition at $20{ }^{\circ} \mathrm{C}$ and $40 \% \mathrm{RH}$. It was found that ECM occurred and the trace amount of $\mathrm{H}_{2} \mathrm{~S}$ reacted easily with $\mathrm{Pb}$ to form $\mathrm{PbS}$. 


\section{Effect of electric field}

Once a bias voltage is applied across two oppositely electrodes, an electric field is generated between the two electrodes. The magnitude of electric field is a function of the bias voltage applied across the electrodes and the distance between the two electrodes, as described in eqn (23),

$$
E=\frac{V}{d}
$$

where $E$ is the magnitude of electric field, $V$ is the bias voltage and $d$ is the spacing between the two electrodes. As indicated in eqn (3), ${ }^{\mathbf{1 0 2}}$ the higher the magnitude of electric field is applied, the faster the ion migration is. However, for the overall ECM process, it cannot be so simply considered like this, because the bias voltage and the spacing may specifically affect some subprocesses which may determine the ECM behaviors. E.g., a critical bias voltage must be reached for the ECM to occur, ${ }^{148}$ otherwise, no ECM phenomenon can be seen even if the electric field strength is extremely high. The longer time-to-failure can be obtained at a longer spacing even when the electric field strength is much greater than that at smaller spacing, because a longer time is required for the electrolyte layer formation at longer spacing..$^{\mathbf{8 4}}$ Additionally, there are huge differences in ECM behaviors between DC voltage electric field and pulsed (or AC) voltage electric field, although the same electric field strength is employed. Therefore, the effects of bias voltage, the type of bias voltage and spacing on ECM are reviewed separately.

\subsection{Bias voltage}

A bias voltage must be applied across the two electrodes for ECM to occur. The dissolution of metal, ion transport caused by electric field and the reduction of metal ions are greatly affected by the bias voltage.

It has been suggested that there is a bias voltage range, outside which ECM will not occur. ${ }^{148}$ The minimum bias voltage for ECM to occur is determined by the critical potential which is required for dissolution of metal or reduction of metal ions to occur. ${ }^{\mathbf{1 1 0 , 1 1 1 , 1 4 9}}$ The upper limit of voltage range exists. Above this voltage the failure mechanism of circuits tends to change from ECM to other failures, such as dielectric breakdown. ${ }^{\mathbf{1 5 0}}$

Normally, the higher voltage is in this range, the shorter the time-to-failure is if the spacing between the two electrodes is fixed.,.$^{3,64,69,71,148}$ This is because higher voltage enhances the dissolution of metal at anode and the reduction of metal ions at cathode, at the same time, accelerates migration speed of ions, resulting in rapid dendrite growth. ${ }^{64}$ However, some specific points need to be paid attention as well. E.g., at the same spacing higher bias voltage leads to faster reaction rates. In this case, more precipitation such as tin hydroxides which are formed during the migration process will hinder the ion transport and dendrite growth, ${ }^{53}$ while heavy gas evolution at the anode and cathode may also inhibit or even destroy the growth of dendrites. ${ }^{2,46,53}$ This is why under some conditions, as the bias voltage increases the probability of ECM decreases, or the time-to-failure increases.

\subsection{The type of bias voltage}

Three types of bias voltage including DC voltage, pulsed voltage and AC voltage have been employed in the ECM study. Most of the studies focused on ECM under DC voltage, ${ }^{6-47,52-76}$ however, relatively low attention has been drawn onto ECM under AC voltage and pulsed voltage ${ }^{\mathbf{4 8 , 5 1 , 1 5 1 - 1 5 3}}$ although they are also common voltage signals used in the electronics.

The ECM of Sn and Sn solder alloys under DC voltage has been reviewed in detail in above section. The ECM of Sn and Sn solder alloys under pulsed voltage or AC voltage would be apparently different from that under DC voltage, since some processes may be introduced under pulsed and AC voltage, such as the changes in the direction of electric field, and the frequent charging and discharging processes of electrical double layer capacitance. ${ }^{\mathbf{1 1}}$

Until now, only three publications related to the ECM of Sn and Sn alloy under AC voltage or pulsed voltage can be found. ${ }^{48,51,154}$ Verdingovas et al. ${ }^{48}$ studied the ECM of Sn under pulsed voltage using water drop test. It was found that varying of pulse width at a fixed duty cycle had a minor effect under investigated conditions, whereas increasing duty cycle significantly reduces the time-to-failure due to the dendrite formation and increases the charge transferred between the electrodes over time. Zhong et al. ${ }^{\mathbf{5 1 , 1 5 4}}$ investigated the ECM of Sn under unipolar and bipolar square waves using thin electrolyte layer method. Under the unipolar square wave, it was found that at a fixed time period the rate of dendrite growth rate increases with the increasing duty cycle. While for the fixed duty cycle, the prolongation of time period was favorable for the precipitates formation and/or dendrites growth. ${ }^{51}$ For the bipolar square wave, the switch between the voltage and its reverse voltage results in a periodic switch between cathodic polarization and anodic polarization applied on the same electrode surface, periodic changes in the migration direction of ions and a circulation between dendrite growth and its re-dissolution. ${ }^{154}$

\subsection{Spacing}

Spacing refers to the distance between two oppositely charged electrodes. The spacing mainly affects the time of electrolyte layer formation and the time of ion transport. The longer time is needed for the continuous electrolyte layer formation and ion transport at longer spacing. ${ }^{\mathbf{8 4}}$ Therefore, it is generally considered that the time-to-failure decreases with decreasing spacing at the same bias voltage.

\section{Inhibition of ECM of Sn and Sn solder alloys}

The inhibition of ECM of Sn and Sn solder alloys is extremely significant for the improvement of reliability of electronics, however, only a few publications have specifically focused on it. $^{49,155,156}$ According to the ECM mechanisms of Sn and Sn solder alloys and the previous studies regarding the ECM and its 
inhibition of other materials, ${ }^{\mathbf{1 5 , 1 5 2 - 1 6 1}}$ the possible strategies to inhibit the ECM of Sn and Sn solder alloys are summarized, including adding alloy elements, inhibitor, and pulsed or AC voltage.

\subsection{Alloy elements}

The addition of alloy elements can effectively decrease the ECM susceptibility of Sn solder alloys. However, it is worthy to note that the inhibition efficiency strongly depends on operating environment. Takemoto et al. ${ }^{76}$ reported that In-48Sn and Sn$1.2 \mathrm{Al}$ solder alloys were immune to ECM in pure water. Thus these alloys are candidates for ECM resistant solder alloys for practical use. Yu et al. ${ }^{71}$ compared the time-to-failure between $\mathrm{Pb}$-free solder alloys ( $\mathrm{Sn}-\mathrm{Ag}$ and $\mathrm{Sn}-\mathrm{Ag}-\mathrm{Cu}$ ) and $\mathrm{Pb}$ bearing solder alloys ( $\mathrm{Sn}-37 \mathrm{~Pb}$ and $\mathrm{Sn}-36 \mathrm{~Pb}-2 \mathrm{Ag}$ ) in distilled water. It was found that $\mathrm{Pb}$ bearing solder alloys have smaller time-tofailure than $\mathrm{Pb}$-free solder alloy, indicating that $\mathrm{Pb}$-free solder alloys exhibit lower ECM susceptibility in distilled water. Yoo et $a l .{ }^{62}$ compared the time-to-failure of pure $\mathrm{Sn}, \mathrm{Sn}-37 \mathrm{~Pb}$ and $\mathrm{Sn}-55 \mathrm{~Pb}$ solder alloys in $0.001 \mathrm{wt} \% \mathrm{Na}_{2} \mathrm{SO}_{4}$ solution using water drop. They found that the time-to-failure increased with increasing $\mathrm{Pb}$ content. Therefore, it can be considered that the addition of $\mathrm{Pb}$ into solders could improve the ECM resistance of $\mathrm{Sn}$ based solder alloys in the $\mathrm{Na}_{2} \mathrm{SO}_{4}$ solution. As mentioned above, sulfate-containing environment is favorable for a protective film formation on the $\mathrm{Sn}-\mathrm{Pb}$ solder alloys. This protective film can hinder the dissolution of $\mathrm{Sn}$ solder alloys and thereby inhibit the ECM development of Sn-Pb solder alloys.

\subsection{Inhibitor}

Inhibitor is another effective way to improve the ECM resistance of $\mathrm{Sn}$ and $\mathrm{Sn}$ solder alloys. Liao et al. found that citrate ions, ${ }^{\mathbf{4 9}}$ cetyltrimethylammonium bromide $(\mathrm{CTAB})^{\mathbf{1 5 5}}$ and $\mathrm{Na}_{2} \mathrm{~S}^{\mathbf{1 5 6}}$ can effectively inhibit the ECM of tin. Citrate ions could be used to inhibit ECM of Sn in thin electrolyte layer containing $\mathrm{Cl}^{-}$under a certain voltage range. On the one hand, the formation of tincitrate complex species (negatively charged) prevented the migration of tin ions from anode to cathode. On the other hand, the presence of citrate greatly improved the passive ability of Sn in $\mathrm{Cl}^{-}$-containing solution. According to results of the measurements for the exact potential applied on electrode, the potential applied on anode is located in the passive region (see Fig. 9), thereby decreasing the anodic dissolution. ${ }^{49}$ Consequently, the ECM of Sn was effectively inhibited in a certain bias voltage range. The $\mathrm{CTA}^{+}$in CTAB is mainly responsible for the inhibition of ECM through the selective adsorption on the Sn surface. ${ }^{155}$ The inhibition mechanism of $\mathrm{Na}_{2} \mathrm{~S}$ on ECM of $\mathrm{Sn}$ is mainly attributed to the precipitates formation between the anode and cathode. These precipitates acted as a wall-like barrier to hinder the ions transport, which slows ECM rate or even stop ECM of tin. ${ }^{156}$ Ambat et al. ${ }^{44}$ reported that the organic acids in the flux residue can some time act as inhibitors to reduce the migration of $\mathrm{Sn}$, however the exact effect depended on combination of factors such as amount, morphology, and presence of other ions such as chlorides. Therefore, according

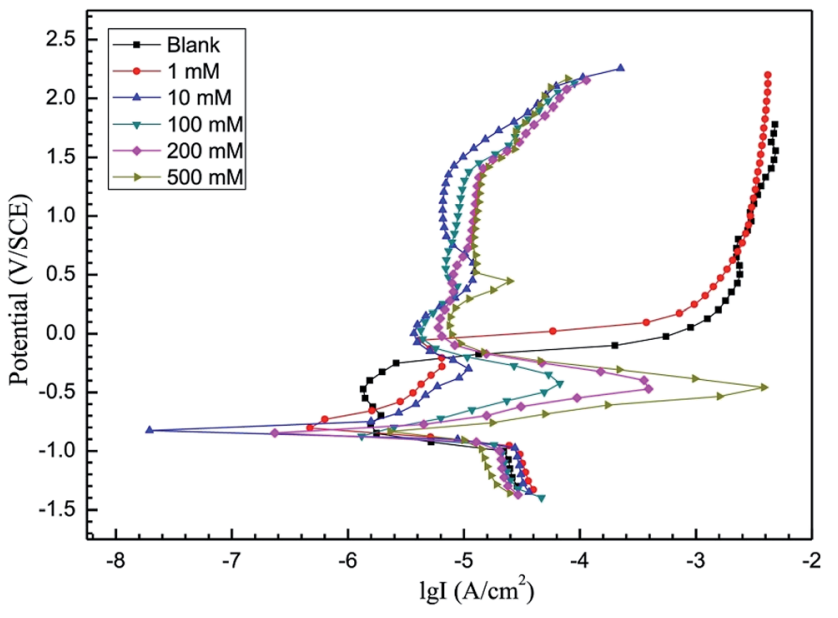

Fig. 9 Polarization curves for tin in solutions containing $1 \mathrm{mM} \mathrm{Cl}^{-}$and various citrate ion concentrations $(0,1,10,100,200,500 \mathrm{mM})$. Reproduced with permission from ref. 49. Copyright 2016, Elsevier.

to the analysis of the formation of precipitates in precipitates section, it can also be expected that if chemicals can cause Sn or alloy elements to form precipitates between anode and cathode or at the electrode surface, they can be used to inhibit the ECM of Sn and Sn solder alloys.

\subsection{Pulsed or AC voltage}

Investigations have indicated that a pulsed voltage can suppress the dendrite growth of Sn under some conditions. ${ }^{48,51}$ Verdingovas et $a .^{48}$ found that there was a suppression effect of decreasing duty cycle on dendrite formation of $\mathrm{Sn}$ as it reduced the rate of the dendrite formation. Zhong et al. ${ }^{51}$ reported that no dendrite growth of Sn could be seen when the duty cycle was equal to 0.1 at the periods from $10 \mathrm{~ms}$ to $1000 \mathrm{~ms}$. These results indicate that ECM of Sn solders can be inhibited by adjusting the parameters of voltage. Similarly, it is also known that pulsed voltage can effectively suppress the $\mathrm{Li}$ dendrites growth in $\mathrm{Li}-$ metal batteries. ${ }^{157,158}$

It is also reported that AC voltage can suppress the ECM development. Chaikin et al. ${ }^{151}$ demonstrated that, when an alternating $60 \mathrm{~Hz}$ voltage was applied between the circuits, far less ECM of Ag was produced, and no ECM of Ag could be detected at higher frequencies. Therefore, the AC could also be expected to inhibit the ECM of Sn and Sn solder alloys. Zhong et al. ${ }^{154}$ also found that the dendrite growth of Sn under bipolar square wave voltage (like AC voltage) was strongly dependent upon the semi-cycle of bipolar square wave voltage. The dendrite growth will not appear if the semicycle is shorter than a critical value.

Accordingly, both pulsed voltage and AC voltage should be the effective candidates to inhibit the ECM of Sn and Sn solder alloys. Especially for some devices where a pulsed or AC voltage signal is needed, the ECM of Sn and Sn solder alloys can probably be inhibited, or even avoided in some conditions. 


\section{Conclusions}

In this review, the fundamentals of ECM are first summarized, and then, the development in ECM studies of Sn and Sn solder alloys are reviewed. The main conclusions are drawn as follows:

ECM process can be considered as a consecutive four-step process: (i) electrolyte layer formation, (ii) dissolution of metal, (iii) ion transport and (iv) deposition of metal ions. The electrolyte layer formation is the precondition of ECM to occur, which depends upon the relative humidity, contaminants, temperature, and surface conditions of materials in electronics. The dissolution of metal supplies the metal ions for the subsequent steps. It is therefore considered that its dissolution rate determines the whole ECM process. Ion transport is affected by electrical migration, diffusion and/or convection. The deposition of metal ions generates the dendrites which can short the circuit, ultimately causing the failure of electronics.

Many chemical/electrochemical reactions are involved in during the ECM of $\mathrm{Sn}$ and Sn solder alloys. The precipitate formation cannot only consume the metal ions, but may also hinder the migration of ions. Consequently, the rate or the probability of dendrites growth is suppressed. The dendrites growth may either derive from the reduction of metal ions, or derive from complex ions, depending on the migration environment.

The alloy elements can either reduce the ECM resistance of Sn solder alloys, or promote the ECM. This is dependent upon the alloy element and the migration environment such as the contaminants.

The effect of contaminants on ECM of Sn and Sn solder alloys are rather complicated. Normally, ionic contaminants can accelerate the electrolyte layer formation due to their hygroscopic nature and also increase the conductivity of electrolyte. The mechanism of ECM in contaminant containing electrolyte is contaminant-type and concentration dependent.

There is a bias voltage range, outside which ECM will not occur. Normally, the higher voltage is in this range, the shorter the time-to-failure is if the spacing between the two electrodes is fixed. However, the precipitates formation and the gas evolution at anode and cathode may cause different ECM behaviors. Pulsed and AC voltage can suppress the ECM under some conditions.

Alloy elements, inhibitor and pulsed voltage or AC voltage are the candidates to be employed to inhibit the ECM of Sn and Sn solder alloys to some extent. However, further investigation is needed.

\section{Acknowledgements}

This work supported by Open Fund of State Key Laboratory of Oil and Gas Reservoir Geology and Exploitation (Southwest Petroleum University) (PLN1514), National Natural Science Foundation of China (No. 51601159) and X. Zhong also received support for part of this work from the Alexander von Humboldt Foundation. B. Medgyes would like to also thank the support for the National Research, Development and Innovation Office -
NKFIH, PD 120898 and the János Bolyai Research Scholarship of the Hungarian Academy of Sciences.

\section{References}

1 R. B. Comizzoli, R. P. Frankenthal, P. C. Milner and J. D. Sinclair, Corrosion of electronic materials and devices, Science, 1986, 234, 340.

2 J. J. Steppan, J. A. Roth, L. C. Hall, D. A. Jeannotte and S. P. Carbone, A review of corrosion failure mechanisms during accelerated tests, J. Electrochem. Soc., 1987, 134, 175.

3 S. J. Krumbein, Tutorial: Electrolytic models for metallic electromigration failure mechanisms, IEEE Trans. Reliab., 1995, 44, 539.

4 B. Illés, A. Skwarek, R. Bátorfi, J. Ratajczak, A. Czerwinski, O. Krammer, B. Medgyes, B. Horváth and T. Hurtony, Whisker growth from vacuum evaporated submicron Sn thin films, Surf. Coat. Technol., 2017, 311, 216.

5 B. Illés, T. Hurtony and B. Medgyes, Effect of current load on corrosion induced tin whisker growth from $\mathrm{SnAgCu}$ solder alloys, Corros. Sci., 2015, 99, 313.

6 B. I. Noh and S. B. Jung, Characteristics of environmental factor for electrochemical migration on printed circuit board, J. Mater. Sci.: Mater. Electron., 2008, 19, 952.

7 S. Zhan, M. H. Azarian and M. Pecht, Reliability of printed circuit boards processed using no-clean flux technology in temperature-humidity-bias conditions, IEEE Trans. Device Mater. Reliab., 2008, 8, 426.

8 M. Natsui, H. Asakawa, T. Tanaka, Y. Ohki, T. Maeno and K. Okamoto, Generation mechanism of electrochemical migration in printed wiring board insulation, IEEJ Trans. Electr. Electron. Eng., 2011, 6, 200.

9 D. Komatsu, N. Takahashi, T. Furutani, R. K. Bhandari, K. Sato, N. Jinbo and T. Kariya, Mechanism verification of electrochemical migration of fine $\mathrm{Cu}$ wiring, Jpn. J. Appl. Phys., 2011, 50, 05EA10.

10 J. H. Kim and S. D. Park, Acceleration of applied voltage on metallic ion migration of wires in NTC thermistor temperature sensors, Eng. Failure Anal., 2013, 28, 252.

11 X. He, M. H. Azarian and M. G. Pecht, Analysis of the kinetics of electrochemical migration on printed circuit boards using Nernst-Plank transport equation, Electrochim. Acta, 2014, 142, 1.

12 H. Huang, Z. Pan, X. Guo and Y. Qiu, Effects of direct current electric field on corrosion behavior of copper, Clion migration behavior and dendrites growth under thin electrolyte layer, Trans. Nonferrous Met. Soc. China, 2014, 24, 285.

13 B. Medgyes, B. Illés and G. Harsányi, Electrochemical migration behavior of $\mathrm{Cu}, \mathrm{Sn}, \mathrm{Ag}$, and Sn63/Pb37, J. Mater. Sci.: Mater. Electron., 2012, 23, 551.

14 S. L. Meilink, M. Zamanzadeh, G. W. Warren and P. Wynblatt, Modeling the failure of electronic devices by dendrite growth in bulk and thin layer electrolytes, Corrosion, 1988, 44, 644. 
15 O. Devos, C. Gabrielli, L. Beitone, C. Mace, E. Ostermann and H. Perrot, Growth of electrolytic copper dendrites. II: oxalic acid medium, J. Electroanal. Chem., 2007, 606, 85.

16 C. Xie, X. Tang, J. Chen, B. Song, J. Jin and H. Zhang, Humidity threshold model of numerical control multilayer printed circuit board for electrochemical migration, Qual. Reliab. Eng. Int., 2015, 31, 567.

17 M. S. Jung, S. B. Lee, H. Y. Lee, C. S. Ryu, Y. G. Ko, H. W. Park and Y. C. Joo, Improvement of electrochemical migration resistance by $\mathrm{Cu} / \mathrm{Sn}$ intermetallic compound barrier on $\mathrm{Cu}$ in printed circuit board, IEEE Trans. Device Mater. Reliab., 2014, 14, 382.

18 C. Xie, X. Tang, J. Chen, B. Song, J. Jin and H. Zhang, Reliability analysis and accelerated statistical model of CNC PCB for electrochemical migration, IEEE Trans. Device Mater. Reliab., 2014, 14, 90.

19 C. Zorn and N. Kaminski, Temperature Humidity bias (THB) testing on IGBT modules at high bias levels, CIPS 2014, $8^{\text {th }}$ International Conference on Integrated Power Electronics Systems, Nuremberg, Germany, February 25-27 2014.

20 B. Medgyes, X. Zhong and G. Harsányi, The effect of chloride ion concentration on electrochemical migration of copper, J. Mater. Sci.: Mater. Electron., 2015, 26, 2010.

21 P. Yi, C. Dong, K. Xiao and X. Li, Surface failure analysis of a field-exposed copper-clad plate in a marine environment with industrial pollution, Appl. Surf. Sci., 2017, 399, 608.

22 P. Yi, K. Xiao, K. Ding, C. Dong and X. Li, Surface failure mechanism of PCB-ENIG in typical outdoor atmospheric environments, Mater. Res. Bull., 2017, 91, 179.

23 P. Yi, K. Xiao, K. Ding, C. Dong and X. Li, Electrochemical migration behavior of copper-clad laminate and electroless nickel/immersion gold printed circuit boards under thin electrolyte layers, Materials, 2017, 10, 137.

24 M. V. Coleman and A. E. Winster, Silver migration in thick film conductors and chip attachment resins, Microelectron. J., 1981, 12, 23.

$25 \mathrm{~S}$. Yang, J. Wu and A. Christou, Initial stage of silver electrochemical migration degradation, Microelectron. Reliab., 2006, 46, 1915.

$26 \mathrm{Y}$. $\mathrm{Li}$ and C. P. Wong, Monolayer protection for electrochemical migration control in silver nanocomposite, Appl. Phys. Lett., 2006, 89, 112112.

27 Y. R. Yoo, H. S. Nam, J. Y. Jung, S. B. Lee, Y. B. Park, Y. C. Joo and Y. S. Kim, Effects of $\mathrm{Ag}$ and $\mathrm{Cu}$ additions on the electrochemical migration susceptibility of $\mathrm{Pb}$-free solders in $\mathrm{Na}_{2} \mathrm{SO}_{4}$ solution, Corros. Sci. Technol., 2007, 6, 50.

28 B. Medgyes, B. Illés, R. Berényi and G. Harsányi, In situ optical inspection of electrochemical migration during THB tests, J. Mater. Sci.: Mater. Electron., 2011, 22, 694.

29 B. I. Noh, J. W. Yoon, K. S. Kim, Y. C. Lee and S. B. Jung, Microstructure, electrical properties, and electrochemical migration of a directly printed $\mathrm{Ag}$ pattern, J. Electron. Mater., 2011, 40, 35.

30 D. Minzari, M. S. Jellesen, P. Møller and R. Ambat, Morphological study of silver corrosion in highly aggressive sulfur environments, Eng. Failure Anal., 2011, 18, 2126.

31 G. Q. Lu, C. Yan, Y. Mei and X. Li, Dependence of electrochemical migration of sintered nanosilver on chloride, Mater. Chem. Phys., 2015, 151, 18.

32 B. Medgyes, B. Illés and G. Harsányi, Effect of water condensation on electrochemical migration in case of FR4 and polyimide substrates, J. Mater. Sci.: Mater. Electron., 2013, 24, 2315.

33 J. W. Yoon, B. I. Noh and S. B. Jung, Electrical properties and electrochemical migration characteristics of directly printed Ag patterns with various sintering conditions, Microelectron. Reliab., 2014, 54, 410.

34 K. S. Kim, J. O. Bang and S. B. Jung, Electrochemical migration behavior of silver nanopaste screen-printed for flexible and printable electronics, Curr. Appl. Phys., 2013, 13, S190.

35 K. S. Kim, Y. T. Kwon, Y. H. Choa and S. B. Jung, Electrochemical migration of $\mathrm{Ag}$ nanoink patterns controlled by atmospheric-pressure plasma, Microelectron. Eng., 2013, 106, 27.

36 B. I. Noh, J. W. Yoon, K. S. Kim, S. Kang and S. B. Jung, Electrochemical migration of directly printed $\mathrm{Ag}$ electrodes using Ag paste with epoxy binder, Microelectron. Eng., 2013, 103, 1.

37 C. H. Tsou, K. N. Liu, H. T. Lin and F. Y. Ouyang, electrochemical migration of fine-pitch nanopaste $\mathrm{Ag}$ interconnects, J. Electron. Mater., 2016, 45, 6123.

38 G. Q. Lu, W. Yang, Y. H. Mei, X. Li, G. Chen and X. Chen, Mechanism of migration of sintered nanosilver at high temperatures in dry air for electronic packaging, IEEE Trans. Device Mater. Reliab., 2014, 14, 311.

39 R. Riva, C. Buttay, B. Allard and P. Bevilacqua, Migration issues in sintered-silver die attaches operating at high temperature, Microelectron. Reliab., 2013, 53, 1592.

40 Y. Zhou and Y. Huo, The comparison of electrochemical migration mechanism between electrodeless silver plating and silver electroplating, J. Mater. Sci.: Mater. Electron., 2016, 27, 931.

41 G. Ripka and G. Harsányi, Electrochemical migration in thick-film IC-S, Electrocomponent Sci. Technol., 1985, 11, 281.

42 D. Minzari, M. S. Jellesen, P. Møller and R. Ambat, On the electrochemical migration mechanism of tin in electronics, Corros. Sci., 2011, 53, 3366.

43 D. Minzari, F. B. Grumsen, M. S. Jellesen, P. Møller and R. Ambat, Electrochemical migration of tin in electronics and microstructure of the dendrites, Corros. Sci., 2011, 53, 1659.

44 R. Ambat, M. S. Jellesen, D. Minzari, U. Rathinavelu, M. A. K. Johnsen, P. Westermann and P. Møller, Solder flux residues and electrochemical migration failures of electronic devices, Proceedings of the Eurocorr, 2009, p. 8141.

45 D. Minzari, M. S. Jellesen, P. Møller, P. Wahlberg and R. Ambat, Electrochemical migration on electronic chip resistors in chloride environments, IEEE Trans. Device Mater. Reliab., 2009, 9, 392. 
46 V. Verdingovas, M. S. Jellesen and R. Ambat, Influence of sodium chloride and weak organic acids (flux residues) on electrochemical migration of tin on surface mount chip components, Corros. Eng., Sci. Technol., 2013, 48, 426.

47 V. Verdingovas, M. S. Jellesen and R. Ambat, Impact of $\mathrm{NaCl}$ contamination and climatic conditions on the reliability of printed circuit board assemblies, IEEE Trans. Device Mater. Reliab., 2014, 14, 42.

48 V. Verdingovas, M. S. Jellesen and R. Ambat, Effect of pulsed voltage on electrochemical migration of tin in electronics, J. Mater. Sci.: Mater. Electron., 2015, 26, 7997.

49 B. Liao, Z. Chen, Y. Qiu, G. Zhang and X. Guo, Effect of citrate ions on the electrochemical migration of tin in thin electrolyte layer containing chloride ions, Corros. Sci., 2016, 112, 393.

50 X. Zhong, G. Zhang and X. Guo, The effect of electrolyte layer thickness on electrochemical migration of tin, Corros. Sci., 2015, 96, 1.

51 X. Zhong, X. Guo, Y. Qiu, Z. Chen and G. Zhang, In situ study the electrochemical migration of tin under unipolar square wave electric field, J. Electrochem. Soc., 2013, 160, D495.

52 X. Zhong, G. Zhang, Y. Qiu, Z. Chen and X. Guo, In situ study the dependence of electrochemical migration of tin on chloride, Electrochem. Commun., 2013, 27, 63.

53 X. Zhong, G. Zhang, Y. Qiu, Z. Chen and X. Guo, Electrochemical migration of tin in thin electrolyte layer containing chloride ions, Corros. Sci., 2013, 74, 71.

54 B. Medgyes, D. Szivós, S. Ádám, L. Tar, P. Tamási, L. Gál, R. Berényi and G. Harsányi, Electrochemical migration of $\mathrm{Sn}$ and $\mathrm{Ag}$ in $\mathrm{NaCl}$ environment, 2016 IEEE $22^{\text {nd }}$ International Symposium for Design and Technology in Electronic Packaging, 2016, p. 274.

55 B. Medgyes, B. Horváth, B. Illés, T. Shinohara, A. Tahara, G. Harsányi and O. Krammer, Microstructure and elemental composition of electrochemically formed dendrites on lead-free micro-alloyed low Ag solder alloys used in electronics, Corros. Sci., 2015, 92, 43.

56 C. Dominkovics and G. Harsányi, Fractal description of dendrite growth during electrochemical migration, Microelectron. Reliab., 2008, 48, 1628.

57 C. Dominkovics and G. Harsányi, Fractal description of dendrite growth during electrochemical migration, Electr. Eng., 2008, 52, 13.

58 B. Illés, B. Medgyes and A. Horváth, Electrochemical migration behavior of surface finishes after vapour phase reflow soldering, 2014 IEEE $20^{\text {th }}$ International Symposium for Design and Technology in Electronic Packaging, 2014, p. 253.

59 B. Medgyes, R. Berényi, L. Jakab and G. Harsányi, Real-time monitoring of electrochemical migration during environmental tests, Electronics Technology, 2009, DOI: 10.1109/isse.2009.5207046.

60 S. B. Lee, H. Y. Lee, M. S. Jung, Y. B. Park and Y. C. Joo, Effect of the composition of $\mathrm{Sn}-\mathrm{Pb}$ alloys on the microstructure of filaments and the electrochemical migration characteristics, Met. Mater. Int., 2011, 17, 617.
61 Y. R. Yoo and Y. S. Kim, Influence of electrochemical properties on electrochemical migration of $\mathrm{SnPb}$ and $\mathrm{SnBi}$ solders, Met. Mater. Int., 2010, 16, 739.

62 Y. R. Yoo and Y. S. Kim, Elucidation of the relationship between the electrochemical migration susceptibility of $\mathrm{SnPb}$ solders for PCBs and the composition of the resulting dendrites, Met. Mater. Int., 2010, 16, 613.

63 J. Y. Jung, S. B. Lee, H. Y. Lee, Y. C. Joo and Y. B. Park, Electrochemical migration characteristics of eutectic Sn$\mathrm{Pb}$ solder alloy in $\mathrm{NaCl}$ and $\mathrm{Na}_{2} \mathrm{SO}_{4}$ solutions, J. Electron. Mater., 2009, 38, 691.

64 S. B. Lee, M. S. Jung, H. Y. Lee, T. Kang and Y. C. Joo, Effect of bias voltage on the electrochemical migration behaviors of Sn and Pb, IEEE Trans. Device Mater. Reliab., 2009, 9, 483.

65 J. Y. Jung, S. B. Lee, H. Y. Lee, Y. C. Joo and Y. B. Park, Effect of ionization characteristics on electrochemical migration lifetimes of $\mathrm{Sn}-3.0 \mathrm{Ag}-0.5 \mathrm{Cu}$ solder in $\mathrm{NaCl}$ and $\mathrm{Na}_{2} \mathrm{SO}_{4}$ solutions, J. Electron. Mater., 2008, 37, 1111.

66 J. Y. Jung, S. B. Lee, Y. C. Joo, H. Y. Lee and Y. B. Park, Anodic dissolution characteristics and electrochemical migration lifetimes of $\mathrm{Sn}$ solder in $\mathrm{NaCl}$ and $\mathrm{Na}_{2} \mathrm{SO}_{4}$ solutions, Microelectron. Eng., 2008, 85, 1597.

67 Y. R. Yoo and Y. S. Kim, Influence of corrosion properties on electrochemical migration susceptibility of $\mathrm{SnPb}$ solders for PCBs, Met. Mater. Int., 2007, 13, 129.

68 S. B. Lee, J. Y. Jung, Y. R. Yoo, Y. B. Park, Y. S. Kim and Y. C. Joo, Dominant migration element in electrochemical migration of eutectic $\mathrm{SnPb}$ solder alloy, 2006 Electronic Components and Technology Conference, 2006, p. 621.

69 B. I. Noh, J. B. Lee and S. B. Jung, Effect of surface finish material on printed circuit board for electrochemical migration, Microelectron. Reliab., 2008, 48, 652.

70 B. I. Noh and S. B. Jung, Behavior of electrochemical migration with solder alloys on printed circuit boards (PCBs), Circuit World, 2008, 34, 8.

71 D. Q. Yu, W. Jillek and E. Schmitt, Electrochemical migration of $\mathrm{Sn}-\mathrm{Pb}$ and lead free solder alloys under distilled water, J. Mater. Sci.: Mater. Electron., 2006, 17, 219.

72 D. Q. Yu, W. Jillek and E. Schmitt, Electrochemical migration of lead free solder joints, J. Mater. Sci.: Mater. Electron., 2006, 17, 229.

73 Y. H. Xia, W. Jillek and E. Schmitt, In situ observation on electrochemical migration of lead-free solder joints under water drop test, 2008 International Conference on Electronic Packaging Technology \& High Density Packaging, 2008, DOI: 10.1109/icept.2008.4607147.

74 X. He, M. H. Azarian and M. G. Pecht, Evaluation of electrochemical migration on printed circuit boards with lead-free and tin-lead solder, J. Electron. Mater., 2011, 40, 1921.

75 C. Sarveswaran, N. K. Othman, M. Yusuf Tura Ali, F. Che Ani and Z. Samsudin, Investigation of electrochemical migration on Sn-0.7Cu-0.3Ag-0.03P-0.005Ni solder alloy in $\mathrm{HNO}_{3}$ solution, AIP Conf. Proc., 2015, 1678, 040003, DOI: 10.1063/1.4931260. 
76 T. Takemoto, R. M. Latanision, T. W. Eagar and A. Matsunawa, Electrochemical migration test of solder alloys in pure water, Corros. Sci., 1997, 39, 1415.

77 G. Harsányi, Irregular effect of chloride impurities on migration failure reliability: contradictions or understandable?, Microelectron. Reliab., 1999, 39, 1407.

78 G. Harsányi, Electrochemical processes resulting in migrated short failures in microcircuits, IEEE Trans. Compon., Packag., Manuf. Technol., Part A, 1995, 18, 602.

79 N. L. Sbar, Bias-humidity performance of encapsulated and unencapsulated Ti-Pd-Au thin-film conductors in an environment contaminated with $\mathrm{Cl}_{2}$, IEEE Trans. Parts, Hybrids, Packag., 1976, 12, 176.

80 E. Brambilla, P. Brambilla, C. Canali, F. Fantini and M. Vanzi, Anodic gold corrosion in plastic encapsulated devices, Microelectron. Reliab., 1983, 23, 577.

81 C. F. Commbs, Printed Circuits Handbook, McGraw-Hill Professional, 2007.

82 S. B. Lee, Y. R. Yoo, J. Y. Jung, Y. B. Park, Y. S. Kim and Y. C. Joo, Electrochemical migration characteristics of eutectic $\mathrm{SnPb}$ solder alloy in printed circuit board, Thin Solid Films, 2006, 504, 294.

$83 \mathrm{~W}$. Lawson, The effects of design and environmental factors on the reliability of electronic products, $\mathrm{PhD}$ thesis, University of Salford, UK, 2007.

84 S. Zhan, M. H. Azarian and M. G. Pecht, Surface insulation resistance of conformally coated printed circuit boards processed with no-clean flux, IEEE Trans. Electron. Packag. Manuf., 2006, 29, 217.

85 S. Lee and R. W. Staehle, Adsorption studies of water on copper, nickel, and iron using the quartz-crystal microbalance technique: Assessment of BET and $\mathrm{FHH}$ models of adsorption, Mater. Corros., 1997, 48, 86.

86 D. W. Rice, R. J. Cappell, P. B. P. Phipps and P. Peterson, Indoor atmospheric corrosion of copper, nickel, cobalt, and iron, in atmospheric corrosion, ed. W. H. Ailor, Wiley, New York, 1982.

87 M. Stratmann and H. Streckel, On the atmospheric corrosion of metals which are covered with thin electrolyte layers-I. Verification of the experimental technique, Corros. Sci., 1990, 30, 681.

88 R. Hienonen and R. Lahtinen, Corrosion and climatic effects in electronics, VTT, Finland, 2007.

89 A. Nishikata, Y. Ichihara, Y. Hayashi and T. Tsuru, Influence of electrolyte layer thickness and $\mathrm{pH}$ on the initial stage of the atmospheric corrosion of iron, $J$. Electrochem. Soc., 1997, 144, 1244.

90 X. Zhong, G. Zhang, Y. Qiu, Z. Chen, X. Guo and C. Fu, The corrosion of tin under thin electrolyte layers containing chloride, Corros. Sci., 2013, 66, 14.

91 X. Liao, F. Cao, L. Zheng, W. Liu, A. Chen, J. Zhang and C. Cao, Corrosion behavior of copper under chloridecontaining thin electrolyte layer, Corros. Sci., 2011, 53, 3289.

92 Y. L. Cheng, Z. Zhang, F. H. Cao, J. F. Li, J. Q. Zhang, J. M. Wang and C. N. Cao, A study of the corrosion of aluminum alloy 2024-T3 under thin electrolyte layers, Corros. Sci., 2004, 46, 1649.
93 T. Zhang, C. Chen, Y. Shao, G. Meng, F. Wang, X. Li and C. Dong, Corrosion of pure magnesium under thin electrolyte layers, Electrochim. Acta, 2008, 53, 7921.

94 G. W. Warren, P. Wynblatt and M. Zamanzadeh, The role of electrochemical migration and moisture adsorption on the reliability of metallized ceramic substrates, J. Electron. Mater., 1989, 18, 339.

95 X. Zhong, S. Yu, L. Chen, J. Hu and Z. Zhang, Test methods for electrochemical migration: a review, J. Mater. Sci.: Mater. Electron., 2017, 28, 2279.

96 D. Beaglehole and H. K. Christenson, Vapor adsorption on mica and silicon: entropy effects, layering, and surface forces, J. Phys. Chem., 1992, 96, 3395.

97 P. B. Miranda, L. Xu, Y. R. Shen and M. Salmeron, Ice like water monolayer adsorbed on mica at room temperature, Phys. Rev. Lett., 1998, 81, 5876.

98 D. B. Asay, A. L. Barnette and S. H. Kim, Effects of surface chemistry on structure and thermodynamics of water layer at solid-vapor interfaces, J. Phys. Chem. C, 2009, 113, 2128.

99 S. Yamamoto, T. Kendelewicz, J. T. Newberg, G. Ketteler, D. E. Starr, E. R. Mysak, K. J. Anderson, H. Ogasawara, H. Bluhm, M. Salmeron, G. E. Brown and A. Nilsson, Water adsorption on $\alpha-\mathrm{Fe}_{2} \mathrm{O}_{3}$ (0001) at near ambient conditions, J. Phys. Chem. C, 2010, 114, 2256.

100 O. Karsliğlu, S. Nemsak, I. Zegkinoglou, A. Shavorskiy, M. Hartl, F. Salmassi, E. M. Gullikson, M. L. Ng, C. Rameshan, B. Rude, D. Bianculli, A. A. Cordones, S. Axnanda, E. J. Crumlin, P. N. Ross, C. M. Schneider, Z. Hussain, Z. Liu, C. S. Fadley and H. Bluhm, Aqueous solution/metal interfaces investigated in operando by photoelectron spectroscopy, Faraday Discuss., 2015, 180, 35.

101 J. L. Barton and J. O. M. Bockris, The electrolytic growth of dendrites from ionic solutions, Proc. R. Soc. London, Ser. A, 1962, 268, 485.

102 J. O. M. Bockris and A. K. N. Reddy, Modern electrochemistry, Plenum press, New York, 1970.

103 H. Similion, N. V. Steen, H. Terryn and J. Deconinck, Geometry influence on corrosion in dynamic thin film electrolytes, Electrochim. Acta, 2016, 209, 149.

104 B. I. Noh, J. W. Yoon, W. S. Hong and S. B. Jung, Evaluation of electrochemical migration on flexible printed circuit boards with different surface finishes, J. Electron. Mater., 2009, 38, 902.

105 V. Fleury, J. N. Chazalviel and M. Rosso, Theory and experimental evidence of electroconvection around electrochemical deposits, Phys. Rev. Lett., 1992, 68, 2492.

106 V. Fleury, J. N. Chazalviel and M. Rosso, Coupling of drift, diffusion, and electroconvection, in the vicinity of growing electrodeposits, Phys. Rev. E: Stat. Phys., Plasmas, Fluids, Relat. Interdiscip. Top., 1993, 48, 1279.

107 A. R. Despic and K. I. Popov, Modern aspects of electrochemistry, Plenum Press, New York, 1972.

108 M. Sun, H. Liao, K. Liu and H. Zheng, Structural and morphological evolution of lead dendrites during electrochemical migration, Sci. Rep., 2013, 3, 3227. 
109 A. Nishikata, Y. Ichihara and T. Tsuru, An application of electrochemical impedance spectroscopy to atmospheric corrosion study, Corros. Sci., 1995, 37, 897.

110 J. H. Shyu, Roughness evolution and dendritic growth in electrodeposition, PhD thesis, Case Western Reserve University, 1982.

111 K. I. Popov, L. J. Djukic, M. G. Pavlović and M. D. Maksimović, The critical overpotential for copper dendrite formation, J. Appl. Electrochem., 1979, 9, 527.

112 M. Schlesinger and M. Paunovic, Modern electroplating, John Wiley, New York, 4th edn, 2000.

113 J. E. Gunn, S. K. Malik and P. M. Mazumdar, Highly accelerated temperature and humidity stress test technique (HAST), Reliability Physics Symposium, 19th Annual, 1981, DOI: 10.1109/irps.1981.362972.

114 S. Krumbein, Metallic electrochemical migration phenomena, IEEE Trans. Compon., Hybrids, Manuf. Technol., 1988, 11, 5.

115 D. Minzari, Investigation of electronic corrosion mechanisms, PhD thesis, Technical University of Denmark, 2010.

116 J. A. Frankin, Atlas of Electrochemical Equilibria in Aqueous Solution, National Association of Corrosion Engineers, Houston, Texas, USA, 1974.

117 F. Séby, M. Potin-Gautier, E. Giffaut and O. F. X. Donard, A critical review of thermodynamic data for inorganic tin species, Geochim. Cosmochim. Acta, 2001, 65, 3041.

118 D. R. Lide, Handbook of Chemistry and Physics, CRC press: Taylor and Francis Group, New York, 2009.

119 A. G. Masey, N. R. Thompson, B. F. G. Johnson and R. Davis, The chemistry of copper, silver and gold, Pergamon Press, New York, 1975.

120 A. M. S. EI Din and F. M. EI Wahab, On the anodic passivity of tin in alkaline solutions, Electrochim. Acta, 1964, 9, 883.

121 E. E. F. EI-Sherbini, S. M. Abd-EI-Wahab, M. A. Amin and M. A. Deyab, Electrochemical behavior of tin in sodium borate solutions and the effect of halide ions and some inorganic inhibitors, Corros. Sci., 2006, 48, 1885.

122 M. Pourbaix, Atlas of electrochemical equilibria in aqueous solutions, ed. M. Pourbaix, NACE, 1974.

$123 \mathrm{~J}$. Glazer, Microstructure and mechanical properties of $\mathrm{Pb}$ free solder alloys for low-cost electronic assembly: a review, J. Electron. Mater., 1994, 23, 693.

$124 \mathrm{M}$. Abtew and G. Selvaduray, Lead-free solders in microelectronics, Mater. Sci. Eng., R, 2000, 27, 95.

125 T. P. Vianco, Development of alternatives to lead-bearing solders, in Proceedings of the technical program on surface mount international, San Jose, CA, August 19-September 2 1993.

126 R. E. Reed-Hill, Physical metallurgy principles, PWS Publishing Company, Massachusetts, 1994, pp. 306-307.

127 K. J. Puttlitz and G. T. Galyon, Impact of the ROHS directive on high-performance electronic systems, Part II: key reliability issues preventing the implementation of leadfree solders, J. Mater. Sci.: Mater. Electron., 2007, 18, 347.

128 S. Menon, E. George, M. Osterman and M. Pecht, High lead solder (over $85 \%$ ) solder in the electronics industry: RoHS exemptions and alternatives, J. Mater. Sci.: Mater. Electron., 2015, 26, 4021.

129 C. M. L. Wu, D. Q. Yu, C. M. T. Law and L. Wang, Properties of lead-free solder alloys with rare earth element additions, Mater. Sci. Eng., R, 2004, 44, 1.

130 W. R. Osório, D. R. Leiva, L. C. Peixoto, L. R. Garcia and A. Garcia, Mechanical properties of Sn-Ag lead-free solder alloys based on the dendritic array and $\mathrm{Ag}_{3} \mathrm{Sn}$ morphology, J. Alloys Compd., 2013, 562, 194.

131 M. McCormack, S. Jin, G. W. Kammlott and H. S. Chen, New Pb-free solder alloy with superior mechanical properties, Appl. Phys. Lett., 1993, 63, 15.

$132 \mathrm{H}$. Tanaka, Factors leading to ionic migration in lead-free solder, ESPEC Technol. R., 2002, vol. 14, p. 1.

133 B. Medgyes, B. Illés and G. Harsányi, Electrochemical migration of micro-alloyed low $\mathrm{Ag}$ solders in $\mathrm{NaCl}$ solution, Turk. J. Electr. Eng. Comput. Sci., 2013, 57, 49.

134 L. Hua and J. S. Zhang, Corrosion behavior of $64 \mathrm{Sn}-35 \mathrm{Bi}-$ $1 \mathrm{Ag}$ solder doped with $\mathrm{Zn}$ in $\mathrm{NaCl}$ solution and its electrochemical migration characteristics in high humid thermal condition for electronic packaging, IEEE International Conference on Electronic Packaging Technology \& High Density Packaging, Shanghai, China, 2011, p. 1034.

135 X. Shi, G. Hansen, M. Mills, S. Jungwirth and Y. Zhang, Preserving the value of highway maintenance equipment against roadway deicers: a cas study and preliminary cost benefit analysis, Anti-Corros. Methods Mater.Morros, 2016, 63, 1.

136 L. Greenspan, Humidity fixed points of binary saturated aqueous solutions, J. Res. Natl. Bur. Stand., Sect. A, 1977, 81, 89.

137 M. S. Jellesen, D. Minzari, U. Rathinavelu, P. Møller and R. Ambat, Corrosion failure due to flux residues in an electronic add-on device, Eng. Failure Anal., 2010, 17, 1263.

138 V. Verdingovas, M. S. Jellesen, R. Rizzo, H. Coseil and R. Ambat, Impact of hygroscopicity and composition of solder flux residue on the reliability of PCBA under corrosive conditions, Proceedings of Eurocorr, 2013, European Corrosion Congress, Estoril, Portugal, 2013.

139 C. Hunt and L. Zou, The impact of temperature and humidity conditions on surface insulation resistance values for various fluxes, Soldering Surf. Mount Technol., 1999, 11, 36.

140 J. E. Sohn and U. Ray, Weak organic acids and surface insulation resistance, Circuit World, 1995, 21, 22.

141 K. G. Schmitt-Thomas and C. Schmidt, The influence of flux residues on the quality of electronic assemblies, Soldering Surf. Mount Technol., 1994, 6, 4.

$142 \mathrm{X}$. Wei and B. Tolla, Effect of flux systems on electrochemical migration of lead-free assembly, SMTAInternational-2014, 2014, http://www.smta.org/knowledge/ proceedings_abstract.cfm?PROC_ID $=4066$.

143 K. S. Hansen, M. S. Jellesen, P. Møller, P. J. S. Westermann and R. Ambat, Effect of solder flux residues on corrosion of electronics, Reliability and Maintainability Symposium, RAMS 2009 Annual, 2009, DOI: 10.1109/ rams.2009.4914727. 
144 H. Tanaka, F. Ueta, S. Yoshihara and T. Shirakashi, Effects of reflow processing and flux residue on ionic migration of lead-free solder plating using the quartz crystal microbalance method, Mater. Trans., 2001, 42, 2003.

145 V. Verdingovas, M. S. Jellesen and R. Ambat, Solder flux residues and humidity-related failures in electronics: Relative effects of weak organic acids used in no-clean flux systems, J. Electron. Mater., 2015, 44, 1116.

146 M. S. Jellesen, D. Minzari, U. Rathinavelu, P. Møller and R. Ambat, Investigation of electronic corrosion at device level, ECS Trans., 2010, 25, 1.

147 S. Zou, X. Li, C. Dong, K. Ding and K. Xiao, Electrochemical migration, whisker formation, and corrosion behavior of printed circuit board under wet $\mathrm{H}_{2} \mathrm{~S}$ environment, Electrochim. Acta, 2013, 114, 363.

148 J. A. Jachim, G. B. Freeman and L. J. Turbini, Use of surface insulation resistance and contact angle measurements to characterize the interactions of three water soluble fluxes with FR-4 substrates, IEEE Trans. Compon., Packag., Manuf. Technol., Part A, 1997, 20, 443.

149 J. S. Vimala, M. Natesan and S. Rajendran, Corrosion and protection of electronic components in different environmental conditions - an overview, Open Corros. J., 2009, 2, 105.

150 E. Bumiller and C. Hillman, A review of models for time-tofailure due to metallic migration mechanisms, DfR Solutions White Pap., 2006, https:/www.smtnet.com/ library/files/upload/Time-to-

Failure_Metallic_Migration.pdf.

151 S. W. Chaikin, J. Janney, F. M. Church and C. W. McClelland, Silver migration and printed wiring, Ind. Eng. Chem., 1959, 51, 299.

152 G. T. Kohman, H. W. Hermance and G. H. Downes, Silver migration in electrical insulation, Bell Syst. Tech. J., 1955, 34, 1115.
153 E. Tsunashima, Printed circuit board with silver migration prevention, US Patent: US3909680 A, 1975.

154 X. Zhong, L. Chen, J. Hu, Y. Shi, Z. Zhang, D. Zeng and T. Shi, In situ study of the electrochemical migration of tin under bipolar square wave voltage, J. Electrochem. Soc., 2017, 164, D342.

155 B. Liao, Z. Chen, Q. Qiu and X. Guo, Inhibitory effect of cetyltrimethylammonium bromide on the electrochemical migration of tin in thin electrolyte layers containing chloride ions, Corros. Sci., 2017, 118, 190.

156 B. Liao, L. Wei, Z. Chen and X. Guo, $\mathrm{Na}_{2} \mathrm{~S}$-influenced electrochemical migration of tin in a thin electrolyte layer containing chloride ions, RSC Adv., 2017, 7, 15060.

157 M. Z. Mayers, J. W. Kaminski and T. F. Miller, Suppression of dendrite formation via pulse charging in rechargeable lithium metal batteries, J. Phys. Chem., 2012, 116, 26214.

158 A. Aryanfar, D. Brooks, B. V. Merinov, W. A. Goddard, A. J. Colussi and M. R. Hoffmann, Dynamics of lithium dendrite growth and inhibition: pulse charging experiments and Monte Carlo calculations, J. Phys. Chem. Lett., 2014, 5, 1721.

159 C. Hendricks, N. Williard, S. Mathew and M. Pecht, A failure modes, mechanisms, and effects analysis (FMMEA) of lithium-ion batteries, J. Power Sources, 2015, 297, 113.

160 L. C. Zou and C. Hunt, Characterization of the conduction mechanisms in adsorbed electrolytes layers on electronic boards using AC impedance, J. Electrochem. Soc., 2009, 156, C8.

161 J. Kim, M. Park, D. Nam and H. Kwon, Electrochemical migration behavior of a fine-pitch IC substrate by alternating current, J. Nanosci. Nanotechnol., 2014, 14, 8258. 